\title{
Monitoring and modelling the risk of summertime overheating and passive solutions to avoid active cooling in London care homes
}

\author{
Rajat Gupta ${ }^{\mathrm{a}, *}$, Alastair Howard ${ }^{\mathrm{a}}$, Mike Davies ${ }^{\mathrm{b}}$, Anna Mavrogianni ${ }^{\mathrm{b}}$, Ioanna Tsoulou ${ }^{\mathrm{b}}$, Nishesh Jain ${ }^{\mathrm{b}}$, \\ Eleni Oikonomou ${ }^{\mathrm{b}}$, Paul Wilkinson ${ }^{\mathrm{c}}$
}

${ }^{a}$ Low Carbon Building Research Group, School of Architecture, Oxford Brookes University, Oxford, UK

${ }^{\mathrm{b}}$ Institute for Environmental Design and Engineering, University College London, London, UK

${ }^{\mathrm{c}}$ Public Health, Environments and Society, London School of Hygiene E' Tropical Medicine, London, UK

\section{A R T I C L E I N F O}

\section{Article history:}

Received 1 February 2021

Revised 27 July 2021

Accepted 4 August 2021

Available online 30 August 2021

\section{Keywords:}

Care homes

Overheating

Temperature

Monitoring

Thermal simulation

\begin{abstract}
A B S T R A C T
Summertime overheating in care settings has been identified as a key risk and research priority for the health and social care system. This paper examines the current and future risk of summertime overheating in two London-based care homes occupying modern and older buildings. Continuous monitoring of outdoor and indoor temperature in bedrooms, communal areas and offices in summer 2019 helped to establish the prevalence and intensity of overheating. Dynamic thermal simulation (EnergyPlusV8.9) of the two care settings assessed the potential for avoiding active cooling in future climate using passive solutions. In both care settings, indoor temperatures were observed to exceed $30^{\circ} \mathrm{C}$ during daytime hours, significantly higher than the recommended $26^{\circ} \mathrm{C}$ threshold of Public Health England. Although severity of overheating was lower in the older building, overheating was found to be prevalent and prolonged across both care settings with bedroom temperatures higher than lounges especially at night. Thermal simulation analysis showed that, with regards to temperature reduction and cooling load, nighttime ventilation was the single most effective passive solution for both buildings for the current climate, while a combination of night ventilation, external shading and high-albedo external walls was the most effective package solution. By the 2080s, air-conditioning was the most effective solution for reducing temperature, but also had the highest cooling load, highlighting the importance of balancing passive with active measures to improve thermal comfort and reduce cooling loads.
\end{abstract}

(c) 2021 The Author(s). Published by Elsevier B.V. This is an open access article under the CC BY license (http://creativecommons.org/licenses/by/4.0/).

\section{Introduction}

In 2019 about $9 \%$ of the world's population was over 65 years old. By 2050 this is projected to be $16 \%$ [51]. In the UK, $18.5 \%$ of the population was aged 65 and over in 2019 [49], placing it 24 th in the world for countries with the largest populations of 65 + year olds [42]. The proportion of 85 + year olds in the UK is predicted to increase by 36\% between 2015 and 2025 [11]. All of these predictions indicate that the UK care home population - 410,000 in 2017 [11]- will also increase significantly, with demand on state and privately funded care home services also increasing.

In parallel with the aging population, climate predictions indicate that temperatures will continue to rise. Significantly, this will mean an increase in the frequency and severity of heatwaves. Research has shown that heatwave periods coincide with increased levels of mortality, particularly within the elderly population [29]

\footnotetext{
* Corresponding author.

E-mail address: rgupta@brookes.ac.uk (R. Gupta).
}

and those in nursing and care homes [24]. Excessive heat has been linked to several medical conditions, in particular an increased risk of cardiovascular and respiratory disease, heat stroke and dehydration [41,2]. In turn, heat stroke can lead to cell, organ and brain damage, and dehydration to urinary tract infections (UTI's), bloodstream infections, and dizziness, increasing the risk of falls. All of these risks are exacerbated in the elderly. Sleep quality and duration can also be affected by high temperatures, with studies finding that at least half of over-65-year-olds experience difficulty in sleeping [35], and those with dementia can experience $40 \%$ of their bedtime hours awake [16].

In 2003, a ten-day heatwave in England and Wales resulted in a $33 \%$ increase in mortality in those aged 75 and over, and a $42 \%$ increase in mortality for those in nursing homes - compared to a $13.5 \%$ increase in mortality in the under-75's [29]. This increased vulnerability amongst the elderly population to the effects of excessive heat has been found in several studies from around the world $[41,46,12,3]$. By 2050, heat-related mortality could increase by more than $250 \%$, with vulnerable groups such as the elderly 
being responsible for the majority of this [26]. With this in mind, the UK Government's 2017 Climate Change Risk Assessment report and the 2018 National Adaptation Programme identified summertime overheating in care homes as a key risk, and as a research priority for the health and social care setting $[13,14]$.

Historically, given the temperate climate of the UK, a key focus in the design of care homes in the UK has been keeping residents warm. The buildings often have distinct features such as heated corridors - rarely found in dwellings other than those designed for the elderly [30]. Heating systems are routinely designed to operate all year round. Evidence of the 'keep the residents warm' mindset is also found in the inspection criteria of the Care Quality Commission - the independent regulator of all health and social services in England. Inspections include checking room temperatures and questioning staff on how they deal with residents feeling cold, but not on how they deal with residents feeling hot [39]. With this in-built historical bias, many care homes can find themselves ill-prepared to deal with high indoor temperatures caused by prolonged periods of high outdoor temperatures.

In this context, and with limited research on summertime performance of care homes in the UK, this study combined continuous environmental monitoring (indoor and outdoor temperatures) with dynamic thermal simulation to examine the current and future prevalence and severity of summertime overheating in two contrasting case study care homes occupying modern and older buildings. Dynamic thermal simulation (EnergyPlusV8.9) of the two care settings was used to explore the potential for avoiding active cooling in the future using passive solutions under current climate conditions and projected future climates.

\section{Evidence to date}

The relationship between high temperatures and an increase in mortality and morbidity has been established in many studies, particularly using data from 21 st century national and international heatwave events, such as the Europe-wide heatwave of 2003. In the UK, over 2000 deaths were attributed to the 2003 heatwave in England and Wales, with excess mortality less than $14 \%$ in the under-75's and 33\% in those age 75 and over [28]. In this age group, excess was greatest in nursing homes (a $42 \%$ increase) during the heatwave, compared to a $33 \%$ increase in deaths at home [29]. In response to this heatwave, public authorities have proposed action plans to better anticipate and coordinate the response to future heatwave events [46], including improving the performance of buildings and installing sustainable air-cooling systems. A further UK-based study by Hajat in 2007 found that elderly people, especially those in nursing and care homes were most vulnerable to heat mortality [24]. The study recommended specific interventions for people in nursing and care homes.

As well as high daily average temperatures, high nighttime temperatures have been linked to increases in mortality, particularly amongst the elderly. Looking at London-based data from 1993 to 2015, Murage found, compared to daytime exposure to high temperatures, nighttime exposure had a higher mortality risk on stroke, whereas respiratory mortality was most sensitive to daytime temperatures [38]. Hot days followed by hot nights had a greater mortality risk than hot days followed by cool nights. As in other studies, older adults were found to be most vulnerable to the effects of hot nights. A study in 10 care homes in south east England found that residents' bedtimes and getting-up times were often determined by the shift patterns of the staff: residents spending around $11 \mathrm{~h}$ in bed at night but sleeping for significantly less than this [34]: the most dependent residents were particularly affected by this, but even those who were more independent were found to shift their bedtimes to fit with the social norm in the homes. Many medications taken by elderly residents have side effects which include insomnia, and sleep disorders related to breathing and periodic limb movement are known to increase with age, along with an advancement of the circadian rhythm which causes older people to awaken earlier in the morning [35]. High nighttime temperatures would therefore be exacerbating a problem which already exists in many of the residents.

Thermal perception has been shown to change with age: young children with high metabolic rates seemingly not feeling the cold, wearing shorts throughout the winter and shedding their coats when out on walks with their parents; older people with much slower metabolic rates keeping their heating on throughout the summer and wrapping up with cardigans even on the hottest of days. A review of studies investigating the thermal comfort, health and energetic properties of the elderly found that their perceptions of thermal comfort tended to differ from the common comfort indexes such as Predicted Mean Vote and Predicted Percentage of Dissatisfied [47]. This study focussed more on the need to provide the elderly with higher comfort temperatures during winter months, but the differing thermal perceptions of the elderly remains a concern during the hotter summer months.

Looking to the future based on climate and population predictions, heat-related mortality in the UK has been projected to rise by over $250 \%$ by the 2050 's compared to a 2000 -deaths baseline in 2014, with the elderly contributing to this most significantly [25]. This corroborates research by Gasparrini which predicted central and southern parts of Europe experiencing a sharp surge in heat related mortality from a 1990 baseline through to the end of the 21st Century [18].

A summary of key literature on the prevalence of overheating in care homes in the UK is shown in Table 1 which illustrates the risks to the elderly, particularly in the context of the anticipated increase in frequency, duration and intensity of heatwaves. A number of studies have focussed their attention on thermal comfort and heat vulnerability amongst care home residents using monitoring, modelling and interviews with staff and residents. An epidemiologically focused literature review concluded that indoor overheating in care homes arises from an interaction between occupants' susceptibility to heat, their behaviour and the building's location and characteristics [9]. The interrelation of these factors is expected to vary over time with demographic and climate changes. A recent study of a Passivhaus care home in the UK found that residents described themselves as thermally comfortable, whereas staff found themselves uncomfortably warm [48]. Furthermore, it was found that energy calculations in the design of the care home did not consider the typical behaviours and activities of the residents and staff, resulting in energy usage being much higher than predicted by the models.

Care home staff identified the design of care homes as creating challenges to keeping the indoor environment cool, including heating and cooling controls which were difficult to interact with [8]. Research into potential retrofit measures to help care settings cope better with high outdoor temperatures found a key challenge to be the fact that the buildings are in constant use and any works would be constrained by this fact [39]. Nevertheless, researchers have identified some measures which could help. Ground source heat pumps powering underfloor heating would facilitate the removal of radiators (often problematic due to their high temperatures and danger to residents) and provide more stable thermal environments at lower cost [39]. Air-conditioning has been suggested, but energy demand and cost of installation make this prohibitive [7]. Furthermore, whether residents would find the cool airconditioned air acceptable is questionable. Instead, adaptive behaviours - changing clothing, adapting food and drink intake, opening windows - are seen as being both low tech and low cost, making them more feasible to implement.

Thermal simulation models have been used to investigate the effectiveness of different measures to mitigate against the effects 
Table 1

Studies investigating overheating in care homes in the UK.

\begin{tabular}{lll}
\hline No & Study & Methods \\
\hline 1 & {$[7]$} & $\begin{array}{l}\text { One residential care building (UK). Observation of care and conversations } \\
\text { with residents and carers. Outdoor environment also monitored. }\end{array}$ \\
2 & {$[1]$} & $\begin{array}{l}\text { Interviews with older people and their carers (not in care homes) } \\
\text { (London, UK). Themes included perception of vulnerability in relation to } \\
\text { heat-related risks, likely actions in extreme heat. }\end{array}$
\end{tabular}

3 [8] An ethnographic approach: observation and interviews to investigate heatwave vulnerability in 4 London care homes.

Key findings

Understanding how heat vulnerability is constructed through everyday routines and practice helps identify alternative ways to manage heat. Some acknowledged that older people might be adversely affected by the heat, but they did not perceive themselves to be particularly vulnerable. Most reported making 'common sense' behaviour changes during previous heatwaves.

Vulnerability to heat in care homes is produced in a number of ways: (1) design of care homes makes them hard to keep cool; (2) staff/residents unable to interact with heating/cooling controls; (3) perception of cold as dangerous, shaping heat management and normalising excessively warm indoor temperatures; and (4) timetables introducing inflexibility, making adapting to the needs hot weather extremely difficult.

4 [34] Diary data collected over 14 days from 125 residents in 10 care homes in South East England.

Residents spent nearly $11 \mathrm{~h}$ in bed at night, significantly more time than was spent sleeping. Bedtimes and getting-up times for dependent residents influenced by the staff's shift patterns. Staff's 12-hour night shifts promoted an overly long 'nighttime', curbing residents' choices about bedtimes and get up times.

5 [4] Five focus groups conducted with residents in four extra-care schemes in England. One focus group with relatives of residents from a fifth scheme.

6 [43] Dynamic thermal simulation modelled the effect of passive heatwave mitigating interventions for UK dwellings.

7 [19] One care home (UK). Summer environmental and energy monitoring in various locations. 14 interviews (staff, not residents) concerning staff and resident comfort and the operation of the building.

8 [31] 13 interviews with those involved in the design, development and management of extra-care housing (UK).

ndependent living was compromised by building elements that did not take account of reduced physical ability. The buildings were too hot, too brightly lit and poorly ventilated.

Internal wall insulation was less effective and in some cases increased the overheating problem. Solar gains controlled through glazing, using shutters and fixed shading. Combinations of interventions can eliminate overheating and reduce space heating energy use.

Most staff considered the building to be too warm and reported to be (thermally) uncomfortable most of the time.

Typical occupants characterised as vulnerable to cold, at risk from fuel poverty, being burned by hot surfaces or falling from high windows - ideas inscribed into the design of extra-care housing schemes.

Temperature monitoring showed overheating in the current climate. Modelling suggested that improved natural ventilation strategies could help to reduce overheating in future climates. Night cooling and shading more effective than all-day rapid ventilation. vulnerable individuals (elderly/ill health/mobility impairment). Environmental monitoring informed modelling for future climates.

10 [39] Qualitative research in six case study homes, focused on management and staff perspectives and experiences. Explored potential of sustainable thermal technologies in care homes.

11 [50] Five extra-care homes and six care homes (UK): Interviews investigated influence of thermal conditions on use of space, preferred thermal environments and spaces.

12 [52] Six care homes (UK): Interviews with care home owners, managers and staff.

13 [21] Two care and two extra-care homes (UK). Dynamic thermal simulation. Interviews with design team.

14 [20] Two care and two extra-care homes (UK). Temperature monitoring, building surveys, interviews with design and management teams.

15 [48] One Passivhaus care home (UK). Environmental and building energy monitoring, and thermal comfort survey.

Despite potential benefits, infrastructure changes are limited as buildings are in constant use.

When conditions were not considered extreme, preferences for spaces were not usually determined by thermal conditions. However, thermal environment was often cited as an important factor in interviews. Respondents saw care homes' core function to provide thermal comfort. Much more emphasis was placed on keeping residents warm than cool. Consequently, carers routinely overheated, particularly when doing more physical work.

Simulation results demonstrated the magnitude of projected summertime overheating in care settings, yet there was little awareness amongst designers about overheating risks and long-term adaptation approaches such as external shading or cross-ventilation.

Summertime overheating was prevalent, yet little awareness or preparedness existed to implement suitable adaptation strategies. Interviewees perceived cold to represent a bigger threat to occupants' health than excessive heat. Staff found the care home uncomfortably warm whereas residents were comfortable. Energy use was higher than expected due to design models which did not consider the in-practice activities of the care home.

of heatwaves. Interestingly, internal wall insulation was found to be less effective and in some cases increased the overheating problem. More effective measures in limiting solar gains included using shutters and fixed shading such as brize soleil [43]. Natural ventilation strategies and night-cooling strategies have also been found to help reduce overheating in models, but the effectiveness of these measures is diminished in projected future climate scenarios [37].

As the evidence from literature shows, historically, care homes have been designed and built with the aim of keeping residents comfortably warm all year round, with heating systems designed accordingly. Frontline carers and managers are trained to view cold as a danger: an effective strategy during the cold winter months, but when warmer weather arrives, many residents and staff become more vulnerable [22].

The research presented in this paper aims to deepen understanding about the prevalence and severity of overheating within newer and older care home buildings in London. The environmental data is used to validate thermal simulations to investigate physical adaptations which could be made to care homes to mitigate against the risk of overheating in current and future climatic conditions.

\section{Methods}

The research methodology combined continuous monitoring of indoor and outdoor temperature with dynamic thermal simulation.

\subsection{Environmental monitoring}

Temperature was recorded using Hobo UX100, iButton and Hobo MX2301 data loggers (logging at 5-minute intervals), with device specifications provided in Table 2. 
Table 2

Specification, accuracy and resolution of logging devices.

\begin{tabular}{|c|c|c|c|c|c|}
\hline \multirow[t]{2}{*}{ Purpose } & \multirow[t]{2}{*}{ Device } & \multirow[t]{2}{*}{ Measures and details } & \multicolumn{3}{|l|}{ Specification } \\
\hline & & & Range & Accuracy & Resolution \\
\hline \multirow[t]{3}{*}{ Continuous monitoring - 5-minute intervals } & Hobo UX100 & Indoor air temperature & -20 to $+70^{\circ} \mathrm{C}$ & $\pm 0.21^{\circ} \mathrm{C}$ & $0.024^{\circ} \mathrm{C}$ at $25^{\circ} \mathrm{C}$ \\
\hline & iButton DS1922L & Indoor air temperature & -40 to $+85^{\circ} \mathrm{C}$ & $\pm 0.5^{\circ} \mathrm{C}$ & $0.0625^{\circ} \mathrm{C}$ \\
\hline & Hobo MX2301 & Outdoor temperature & -40 to $+70^{\circ} \mathrm{C}$ & $\pm 0.2^{\circ} \mathrm{C}$ & $0.04{ }^{\circ} \mathrm{C}$ \\
\hline
\end{tabular}

The loggers were distributed throughout the two care homes, with locations categorised as 'offices' (staff-only locations), 'lounge/dining rooms' (communal areas for residents and staff), and 'bedrooms' (Table 3). The nomenclature for locations in each home consists of care home i.d. (PA or VI) followed by room type ( $\mathrm{O}=$ office, $\mathrm{L}=$ lounge, $\mathrm{B}=$ bedroom ) and number, followed by floor ( $\mathrm{G}, 1 \mathrm{st}$, etc.) and orientation (N, S, E, W, int = internal). For monitoring purposes, occupied hours for these location types were defined as 09:00-18:00 for offices and 08:00-21:00 for lounges and dining rooms. Bedrooms were more difficult to define in terms of occupancy: some were occupied only at night for sleeping whereas others were occupied almost 24-7, either through personal preference or necessity due to the resident being bedbound. Bedrooms were therefore differentiated by day - 07:00-21:00 - when any occupants were more likely to be awake and conscious of their immediate environmental conditions, and night - 21:00-07:00 when occupants were more likely to be asleep and therefore unable to make changes to their immediate environmental conditions. An outdoor logger was deployed in the garden of each of the two care homes to record localised outdoor temperature. These loggers were placed in shaded locations to protect them from precipitation and direct sunlight.

This form of temperature measurement is used because it is practically challenging to measure dry-bulb or mean radiant temperature in occupied buildings. In reality, the Hobo temperature

Table 3

Location characteristics for data loggers.

\begin{tabular}{|c|c|c|c|}
\hline $\begin{array}{l}\text { Case } \\
\text { study }\end{array}$ & Location type & $\begin{array}{l}\text { Location } \\
\text { code }\end{array}$ & Notes \\
\hline \multirow[t]{8}{*}{ PA } & Office & $\begin{array}{l}\text { PAO1-G- } \\
\text { S }\end{array}$ & Manager's office. \\
\hline & \multirow[t]{2}{*}{$\begin{array}{l}\text { Lounge/dining } \\
\text { room }\end{array}$} & $\begin{array}{l}\text { PAL1- } \\
\text { 1st-S }\end{array}$ & $\begin{array}{l}\text { High-ceilinged lounge with tall sash } \\
\text { windows. High occupancy. }\end{array}$ \\
\hline & & $\begin{array}{l}\text { PAL2-G- } \\
\text { N } \\
\text { PAL3-G- } \\
\text { S }\end{array}$ & $\begin{array}{l}\text { Lounge connected to main dining } \\
\text { room. High occupancy. } \\
\text { Lounge next to main entrance. Low } \\
\text { occupancy. }\end{array}$ \\
\hline & \multirow[t]{4}{*}{ Bedroom } & $\begin{array}{l}\text { PAB1- } \\
1 \text { st-S } \\
\text { PAB2-2- } \\
\text { S }\end{array}$ & $\begin{array}{l}\text { Residents spent most of daytime in } \\
\text { lounges. }\end{array}$ \\
\hline & & $\begin{array}{l}\text { PAB3-G- } \\
\text { S }\end{array}$ & Bedbound resident - occupied 24-7. \\
\hline & & $\begin{array}{l}\text { PAB4- } \\
\text { 2nd-E }\end{array}$ & $\begin{array}{l}\text { Resident chose to spend most of } \\
\text { daytime in chair in room. }\end{array}$ \\
\hline & & $\begin{array}{l}\text { PAB5- } \\
\text { 2nd-S }\end{array}$ & $\begin{array}{l}\text { Resident spent most of daytime in } \\
\text { lounge. }\end{array}$ \\
\hline & outdoor & PA-out & \\
\hline \multirow[t]{5}{*}{ VI } & Office & $\begin{array}{l}\text { VIO1-G- } \\
\text { int }\end{array}$ & $\begin{array}{l}\text { Finance manager's office adjacent to } \\
\text { reception desk and bistro. No natural } \\
\text { light or ventilation. }\end{array}$ \\
\hline & $\begin{array}{l}\text { Lounge/dining } \\
\text { room }\end{array}$ & $\begin{array}{l}\text { VIL1- } \\
\text { 1st-NE } \\
\text { VIL2- } \\
\text { 2nd-NE }\end{array}$ & $\begin{array}{l}\text { TV lounge with kitchenette and double } \\
\text { doors leading to enclosed outdoor area } \\
\text { TV lounge with kitchenette, directly } \\
\text { above VIL1-1st-NE }\end{array}$ \\
\hline & Bedroom & $\begin{array}{l}\text { VIB1- } \\
1 \mathrm{st}-\mathrm{NE}\end{array}$ & $\begin{array}{l}\text { Resident spent most of days in room, } \\
\text { though not bedbound }\end{array}$ \\
\hline & & $\begin{array}{l}\text { VIB2- } \\
\text { 4th-SW }\end{array}$ & $\begin{array}{l}\text { Bedbound resident, but able to leave } \\
\text { the room with assistance }\end{array}$ \\
\hline & outdoor & VI-out & \\
\hline
\end{tabular}

loggers are likely to be recording some (undefined) mix of air and radiant temperature with a component of surface temperature from conduction through the mounting surface [45]. Moreover, this set-up may actually record a temperature closer to that experienced by the occupants than pure dry bulb temperature [33]. Previous overheating monitoring studies using such wall-mounted sensors have previously delivered insights into overheating, such as the dwelling types most at risk [5,32], and building characteristics that can make dwellings more susceptible to overheating [36].

Overheating analysis was conducted on the recorded temperature data. Both static and dynamic (adaptive) metrics were used to identify the prevalence and concentration of overheating within the two case study buildings (Table 4). For static overheating from CIBSE Guide A, 'living areas' in the care homes covered lounges/dining rooms and offices (i.e. all spaces that were not bedrooms). Temperature thresholds were also considered from the Heatwave Plan for England [44]. The static method allows simple calculations to be performed when judging the overheating of a building as it is based on fixed maximum temperature thresholds.

The static method does not account for occupants' ability to adapt to their environment - including external temperatures. Therefore, adaptive overheating criteria were also investigated. This method, developed by Humphreys and Nicol [40], is relevant to free-running buildings such as the two case study care homes. It should be noted that the adaptive method was developed from research into non-domestic buildings, and more research is needed to establish how applicable it is to hybrid buildings such as care homes. Furthermore, the ability of elderly residents, many with underlying health concerns, to adapt to their local environmental conditions may be reduced. The adaptive model derives threshold comfort temperatures on outdoor temperatures. However, the vast majority of residents spend most if not all of their time indoors. Outdoor temperatures may therefore have less influence on the comfort temperatures of the residents than it has on the staff who come and go from the building much more often. Nevertheless, adaptive overheating criteria have been considered, as defined by CIBSE Guide A, and overheating is deemed to have occurred if at least two of the three criteria are met (Table 4).

Overheating has also been considered using CIBSE TM59, which uses a combination of dynamic and static criteria. Criterion A is dynamic, the same as CIBSE TM52 Criterion 1: Hours of exceedance from May to September; criterion B is static, for nighttime hours $10 \mathrm{pm}$ to 7am in bedrooms only, annually. In addition, TM59 states that for care homes, Type I occupancy (sedentary residents) should be assumed (as defined in CIBSE TM52). The case study care homes were not mechanically ventilated, but they did have restricted window openings, and therefore a third criterion, C, is applicable. If any of these criteria are failed, the space is deemed to be overheating. TM59 is intended for design and modelling of buildings using annual data rather than measured data from the limited period presented here (17th June to 31st August 2019). However, the percentage thresholds for annual occupied hours can be converted to actual hours. The analysis therefore considers these threshold number of hours. Although some locations may not have met the overheating criteria in the monitored period, it is not known whether they would have met the criteria had annual data been 
Table 4

Metrics considered for overheating.

\begin{tabular}{|c|c|c|}
\hline Metric & $\begin{array}{l}\text { Overheating } \\
\text { criterion }\end{array}$ & Definition \\
\hline 1 & $\begin{array}{l}\text { CIBSE Guide } \\
\text { A: Static }\end{array}$ & $\begin{array}{l}\text { No more than } 1 \% \text { of occupied hours over } 28^{\circ} \mathrm{C} \text { in } \\
\text { living areas. } \\
\text { No more than } 1 \% \text { or more of occupied hours over } \\
26^{\circ} \mathrm{C} \text { in bedrooms. }\end{array}$ \\
\hline 2 & $\begin{array}{l}\text { Public Health } \\
\text { England }\end{array}$ & $\begin{array}{l}\text { A cool room/area within the building to be available } \\
\text { where temperatures are kept below } 26^{\circ} \mathrm{C} \text {. }\end{array}$ \\
\hline \multirow[t]{4}{*}{3} & $\begin{array}{l}\text { CIBSE TM52: } \\
\text { Dynamic }\end{array}$ & $\begin{array}{l}\text { Threshold comfort temperature: } \mathrm{T}_{\text {threshold }}=0.33 \\
\left(\mathrm{~T}_{\text {acf }}\right)+21.8{ }^{\circ} \mathrm{C} \text { (where } \mathrm{T}_{\text {acf }} \text { is the running mean of } \\
\text { outdoor temperatures) }\end{array}$ \\
\hline & Criterion 1 & $\begin{array}{l}\text { Temperatures are at least } 1{ }^{\circ} \mathrm{C} \text { above the threshold } \\
\text { comfort temperature for no more than } 3 \% \text { of } \\
\text { occupied hours from May to September. }\end{array}$ \\
\hline & Criterion 2 & $\begin{array}{l}\text { Daily weighted exceedance }\left(\mathrm{W}_{\mathrm{e}}\right)<6 \text {. } \\
\mathrm{W}_{\mathrm{e}}=\mathrm{S}\left(\mathrm{DT} \times \mathrm{H}_{\mathrm{DT}}\right) \\
\text { where DT is the temperature difference above }\end{array}$ \\
\hline & Criterion 3 & $\begin{array}{l}\text { Maximum indoor temperature is no more than } 4{ }^{\circ} \mathrm{C} \\
\text { above } T_{\text {threshold. }}\end{array}$ \\
\hline \multirow[t]{4}{*}{4} & CIBSE TM59 & \\
\hline & Criterion A & $\begin{array}{l}\text { For living rooms and bedrooms, no more than } 3 \% \text { of } \\
\text { occupied hours }>=1{ }^{\circ} \mathrm{C} \text { above threshold } \\
\text { temperature from May to September - equivalent } \\
\text { to } 42 \mathrm{~h} \text { in offices, } 60 \mathrm{~h} \text { in lounges and dining rooms, } \\
41 \mathrm{~h} \text { in bedrooms (day) and } 69 \mathrm{~h} \text { in bedrooms } \\
\text { (night). }\end{array}$ \\
\hline & Criterion B & $\begin{array}{l}\text { No more than } 1 \% \text { of overnight hours in bedrooms } \\
\text { (10 pm-7am) over } 26^{\circ} \mathrm{C} \text { annually - equivalent to } \\
33 \mathrm{~h} \text {. }\end{array}$ \\
\hline & Criterion C & $\begin{array}{l}\text { All occupied rooms greater than } 26^{\circ} \mathrm{C} \text { for no more } \\
\text { than } 3 \% \text { of annual occupied hours - equivalent to } \\
99 \mathrm{~h} \text { in offices, } 143 \mathrm{~h} \text { in lounges and dining rooms, } \\
99 \mathrm{~h} \text { in bedrooms (day) and } 164 \mathrm{~h} \text { in bedrooms } \\
\text { (night). }\end{array}$ \\
\hline
\end{tabular}

available. The analysis provides indicative results for TM59 rather than definitive results.

\subsection{Thermal simulation approach}

Thermal simulation models of the two care home settings were developed using DesignBuilder V6 [15], a graphical user interface for the EnergyPlus V8.9 simulation engine [17]. Since a heatwave is considered to be a period with at least a three-day moving average of external temperatures above $21.5^{\circ} \mathrm{C}$ [23], thermal analysis was conducted for a five-day heatwave period (22nd-26th July) for two weather scenarios:

- Current climate using 2019 weather files obtained from the nearest weather stations: London Weather Centre (WMO:37780) for VI and London Heathrow (WMO: 37720) for PA.

- Future climate using Design Summer Year 1 (DSY1) 2080's high emissions scenario weather data from CIBSE (UKCP09).

Inputs for the thermal simulation models were primarily based on site visits and observations, and on physical, technical and occupancy surveys conducted by the research team. Additional inputs, such as building age and construction characteristics, were derived from Reduced SAP (RdSAP) (DECC, 2017). The key baseline simulation inputs and their sources for both case studies are outlined in Table 5.

To ensure modelling robustness, temperatures from the baseline model (using 2019 actual weather data) from typical zones of each type (office, lounge and bedroom) were compared to the monitored data for the heatwave period (Fig. 1 and Fig. 2). The validation checks suggested that the modelled data was a close enough match to the monitored data that it could therefore be
Table 5

Inputs for thermal simulation models.

\begin{tabular}{ll}
\hline Input & Specifications \\
\hline Occupancy & Bedrooms: 1 occupant; Schedule: All day (with \\
& diversity) \\
& Offices: 1 occupant; Schedule: 08:00-18:00 \\
& Lounges: up to 10 occupants: 09:00-22:00 (with \\
& diversity - max. in evenings) \\
& Source: site observations \\
& Power density: $8-10 \mathrm{~W} / \mathrm{m}^{2}$ \\
Lighting and & Operation: linked to occupancy \\
small power & Source: site observations and RdSAP \\
& Window openable area \\
& PA: $12.5 \%$ \\
& VI: $5 \%$ \\
& All zones are naturally ventilated by operable \\
& windows. \\
& Windows are open when the space is occupied and \\
& when indoor temperature exceeds $22{ }^{\circ} \mathrm{C}$ and is higher \\
& than the outdoor temperature. \\
& Source: site observations and CIBSE TM59 \\
& Source: design documents and RdSAP \\
\hline
\end{tabular}

used to assess the future risk of overheating and the potential for reductions through passive building adaptation strategies.

Both monitored and modelled average temperatures were close to or exceeded the $26{ }^{\circ} \mathrm{C}$ threshold. Temperature values and trends between the two datasets were closely aligned, while temperature differences were within an acceptable $2{ }^{\circ} \mathrm{C}$ range [27]. A higher deviation was observed in the bedrooms of both care homes, where differences could be attributed to the uncertainty of nighttime window operation assumption (for the particular bedroom) specified in the thermal models. Since daytime peak temperatures were closely matched, and the objective was to analyse overheating risks, further fitting of the models was not deemed necessary.

Baseline models were then used to assess future overheating risk and to run a set of simulation scenarios in order to evaluate the potential reduction of overheating in current (2019) and future (2080) climates through the use of passive and active strategies (Table 6). These strategies can also be defined as 'hard' (structural) and 'soft' (behavioural) adaptations, the former being inherently more expensive and fixed regardless of the future climate scenario experienced, the latter being relatively low cost and flexible, possible to implement relatively quickly and adapt depending on the climatic circumstances [10]. Baseline scenario S1 used only window operation as a means of thermal regulation. Scenario S2 considered the use of air-conditioning (AC) in the care homes, used around the clock. Scenarios S3, S4 and S5 used different passive design strategies - night ventilation, shading and reflective surfaces - in conjunction with AC. The final scenario (S6) assessed the cumulative effect of each of the passive strategies. For these simulations (depending on simulation specifications) two results were calculated:

1. Area-weighted hourly average internal temperatures for different zone types over the 5-day heatwave period, and

2. Area-weighted hourly peak cooling loads for each care home over the 5-day heatwave period.

\section{Overview of the case study care homes}

The location of the care homes is shown in Fig. 3 with Table 7 providing key characteristics of the two homes. Both homes were privately owned and operated. Case study PA was one of 12 care homes in the southwest of England managed by a company operating since 2006. The original building was constructed during the 
PA

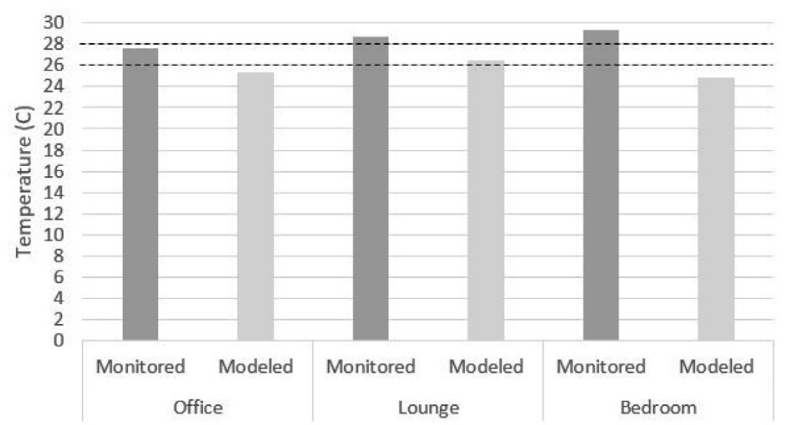

VI

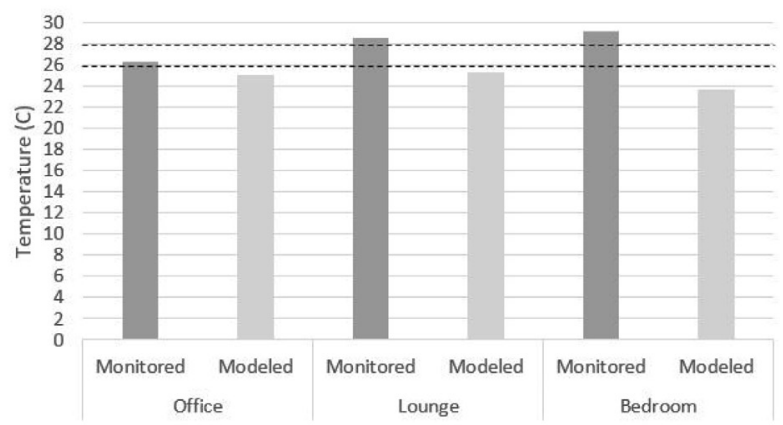

Fig. 1. Monitored vs modelled average temperatures for office, lounge and bedroom during the 5-day heatwave period.

PA Office

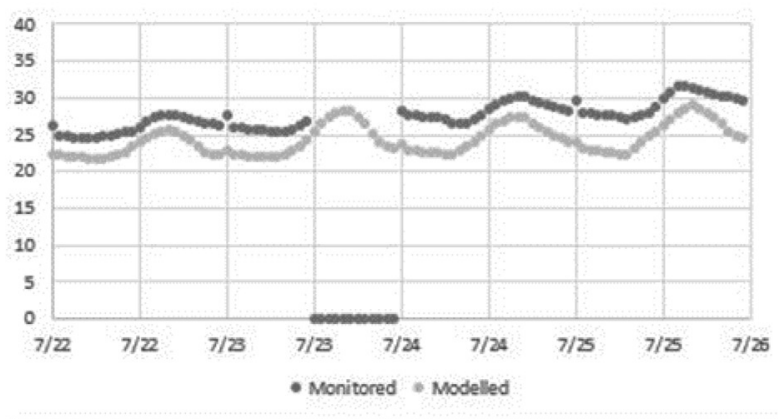

PA_Lounge

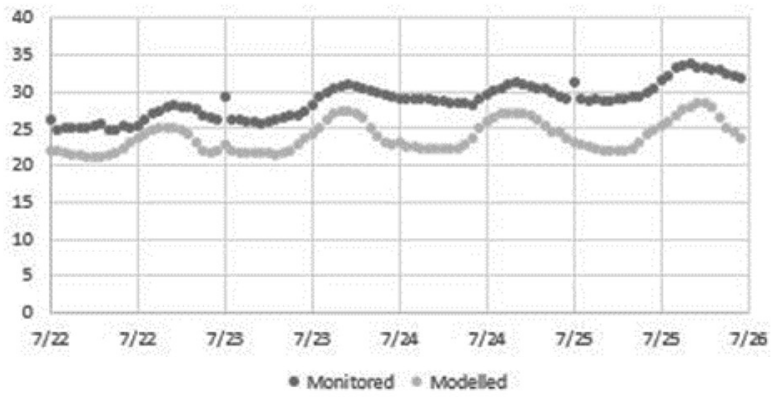

PA Bedroom

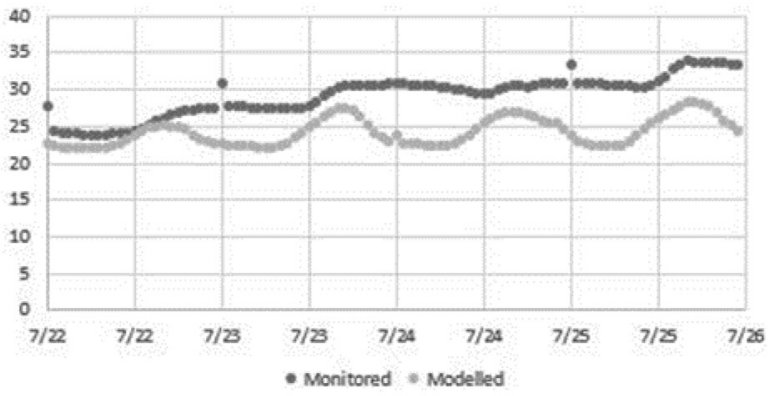

VI_Office

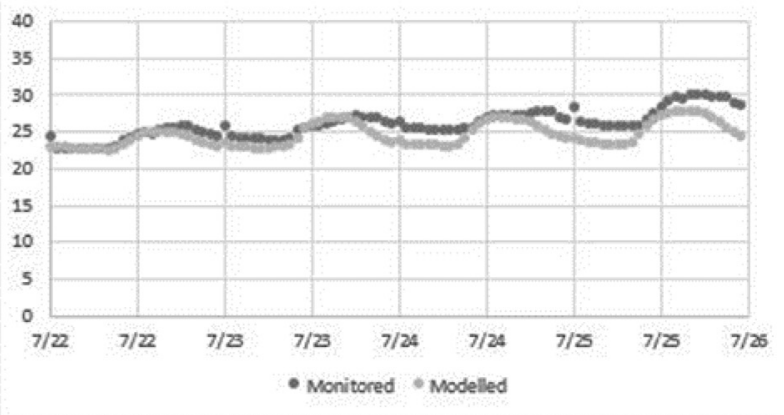

VI_Lounge

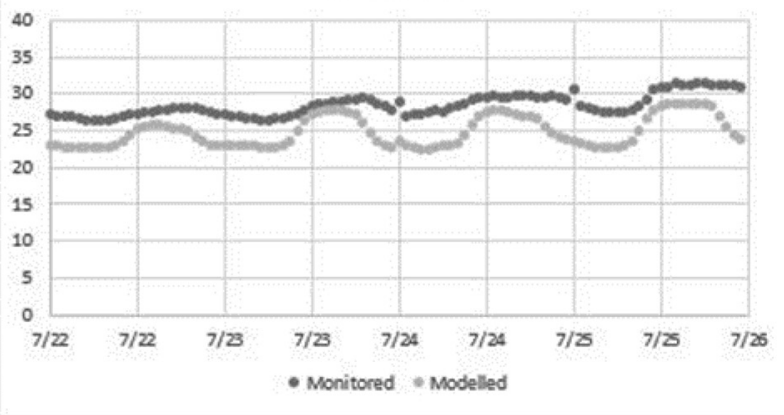

VI_Bedroom

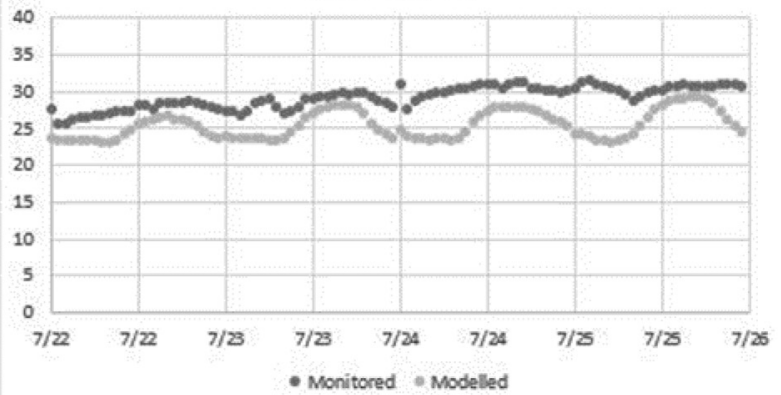

Fig. 2. Monitored vs. modelled temperatures for office, lounge and bedroom during the five-day heatwave period.

Georgian period (1714-1830), and has been added to over the years, serving as a private residence until the 1980 's when it was sold and converted into a nursing care home. The building has a south-facing front and entrance, with the majority of residents' rooms also south-facing, and only around ten north facing. At the front of the home, bordering the small visitor/staff car park is a grassed garden area with a pagoda and shade provided by large trees. The home is surrounded by residential dwellings.

Case study VI, located in west-central London, was purposebuilt in 2013 as the first and only care home managed by a company operating since the same year. It is a large, five-storey building situated next to a hospital and near a large supermarket in a 
Table 6

Building adaptation scenarios for thermal simulations based on passive strategies.

\begin{tabular}{|c|c|c|c|}
\hline ID & Category & Adaptation & Specifications \\
\hline S1 & Baseline & - & \\
\hline S2 & $\mathrm{AC}$ & Hard & AC: open during day (07:00-21:00) and night (21:00-07:00) \\
\hline S3 & AC combined with ventilation & Hard/soft & $\begin{array}{l}\text { AC: open during day } \\
\text { Ventilation: windows open during night }\end{array}$ \\
\hline S4 & AC combined with shading & Hard/hard & $\begin{array}{l}\text { AC: open during day } \\
\text { Shading: window louvres/side fins ( } 0.5 \mathrm{~m} \text { projection) }\end{array}$ \\
\hline S5 & AC combined with reflective surfaces & Hard/hard & $\begin{array}{l}\text { AC: open during day. } \\
\text { Reflective surfaces: high wall albedo }\end{array}$ \\
\hline S6 & $\begin{array}{l}\text { AC combined with ventilation, shading } \\
\text { and reflective surfaces }\end{array}$ & Hard/soft/hard & $\begin{array}{l}\text { AC: open during day } \\
\text { Ventilation: windows open during night Shading: window louvres/side fins } \\
\text { ( } 0.5 \mathrm{~m} \text { projection) Reflective surfaces: high wall albedo }\end{array}$ \\
\hline
\end{tabular}

semi-industrial area. The building's main entrance is to the southeast. The ground floor is home to staff offices, a bistro, a hair salon, cinema, plant room, kitchen and staff rooms. Residents' rooms on the 1st to 4th floors are located either side of corridors which run three sides of a square. From the main stairwell and lift in the southern corner, corridors run to the north-east and northwest, and from the end of the north-west corridor, turning right to another north-east corridor. Lounges and dining rooms are located on each floor. On the first floor, an outdoor 'garden' area is boxed in on 3 sides by bedrooms and lounges, and on the fourth side to the north-east by a high wall.

Both homes catered for a variety of residents, many of whom were suffering from a range of dementia-related issues. Care home VI was a significantly larger care home than PA. Around two-thirds of the bedrooms in PA were south-facing, the rest north or eastfacing. Case study VI was at an approximately $45^{\circ}$ angle to south, with rooms orientated in all possible directions from this: northeast, north-west, south-east, south-west.

\section{Results}

Guided by the definitions used for overheating analysis in CIBSE Guide A, TM52 and TM59, occupied hours were defined as 09:0018:00 in the offices and 08:00-21:00 in the lounges. Bedroom occupancy was more difficult to categorise as it varied so much. Some bedrooms were occupied 24-7, either because the resident was bedbound or because they preferred to stay in their room. Other bedrooms were only occupied for sleeping, with the residents spending their waking hours in the lounges and dining rooms. Environmental analysis for bedrooms was therefore cate- gorised by day - 07:00-21:00, when any occupants were more likely to be awake and conscious of their immediate environmental conditions, and night - 21:00-07:00, when occupants were more likely to be asleep and unable to change their immediate environmental conditions.

\subsection{Indoor and outdoor temperature in case study care homes}

Monitored outdoor temperatures were observed to reach as high as $35.1^{\circ} \mathrm{C}(\mathrm{PA})$ and $38.0^{\circ} \mathrm{C}(\mathrm{VI})$ during the hottest days of the summer. In $\mathrm{PA}$, indoor temperatures reached as high as $34.7{ }^{\circ} \mathrm{C}$ in PAB2-2nd-S and $33.8^{\circ} \mathrm{C}$ in PAL1-1st-S. Within the monitored spaces, temperatures were in the $24-28{ }^{\circ} \mathrm{C}$ range for the majority of the time (interquartile range for all rooms, all hours was $24.8-27.0^{\circ} \mathrm{C}$ ). In no monitored space did the temperature fall below $20^{\circ} \mathrm{C}$ (Fig. 4 and Table 8), even during unoccupied hours. Peaks in outdoor temperatures corresponded to peaks in indoor temperatures, particularly around 23rd-27th July 2019 and 24th29th August 2019 when outdoor temperatures were high during the day and remained relatively high overnight, preventing the building from cooling significantly during 'unoccupied' hours. It is particularly notable that in three of the five monitored bedrooms, mean and median temperatures at night were higher than during the day, and in one room they were the same. Only one of the five bedrooms was cooler at night (PAB3-G-S), and that was only by $0.1{ }^{\circ} \mathrm{C}$. This suggests that the bedrooms did not make use of nighttime cooling strategies such as opening windows, or if they did, these strategies were mitigated by other factors such as residents radiating heat and devices such as televisions or fans generating heat.

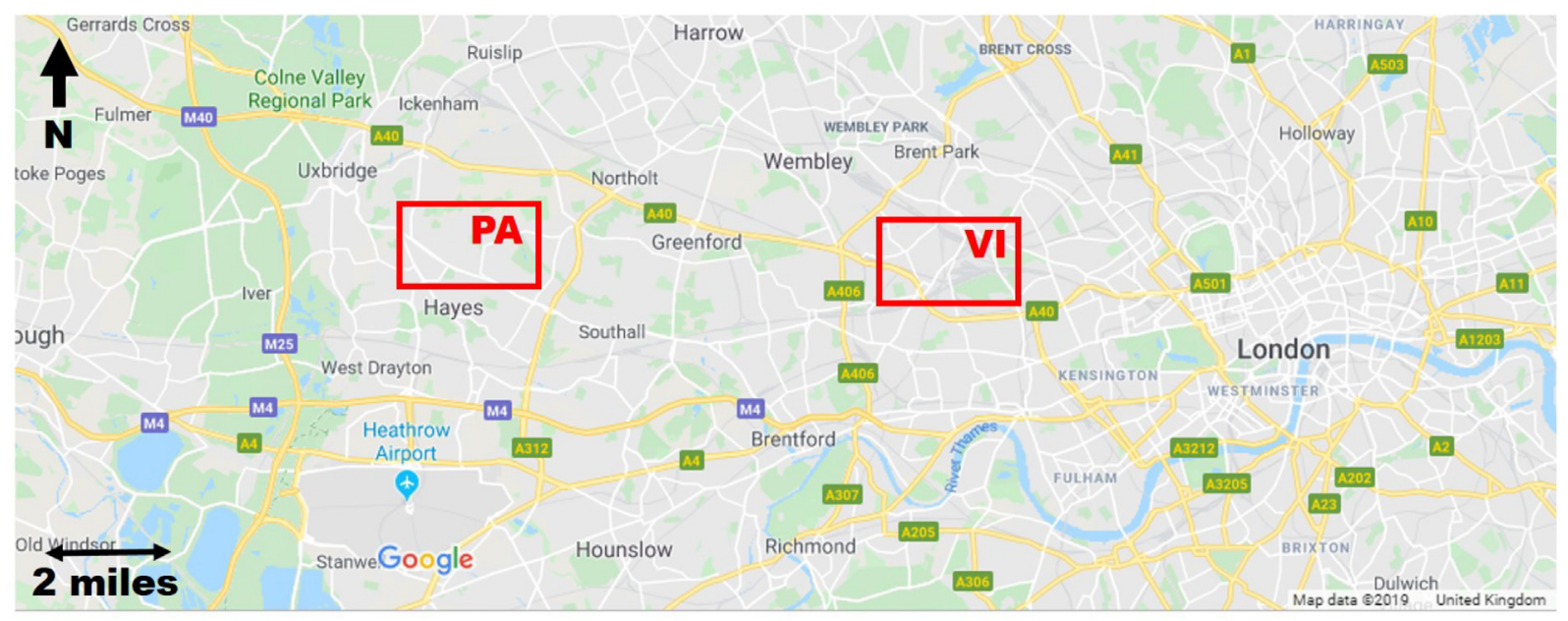

Fig. 3. Location of the two case study care homes. 
Table 7

Key characteristics of case study care homes.

\begin{tabular}{|c|c|c|}
\hline & Care home PA & Care home VI \\
\hline Location & Suburban & Urban \\
\hline Ownership & Privately company & Private company \\
\hline Type of facility & Residential care home & Residential care home \\
\hline Care provided & $\begin{array}{l}\text { Includes dementia, } \\
\text { mental health condition, } \\
\text { old age, physical } \\
\text { disability, sensory } \\
\text { impairment }\end{array}$ & $\begin{array}{l}\text { Includes nursing, } \\
\text { dementia, learning } \\
\text { disabilities, mental } \\
\text { health, sensory } \\
\text { impairments, disease/ } \\
\text { injury }\end{array}$ \\
\hline Age of occupants & $65+$ & $\begin{array}{l}\text { Mainly } 65+\text {, with some } \\
18 \text { + residents with } \\
\text { acute needs. }\end{array}$ \\
\hline CQC rating & Good & Good \\
\hline $\begin{array}{l}\text { Occupancy/max } \\
\text { capacity }\end{array}$ & $36 / 44$ & $115 / 115$ \\
\hline $\begin{array}{l}\text { Gross internal area } \\
\left(\mathrm{m}^{2}\right)\end{array}$ & 1195 & 3196 \\
\hline Year & constructed/converted & $\begin{array}{l}18 \text { th century (manor } \\
\text { house) - converted to } \\
\text { care home in } 1980^{\prime} \mathrm{s} \text {. }\end{array}$ \\
\hline \multicolumn{3}{|l|}{2013 (purpose-built). } \\
\hline $\begin{array}{l}\text { No. of storeys/no. of } \\
\text { rooms }\end{array}$ & 3 storeys, 40 rooms & 5 storeys, 110 rooms \\
\hline $\begin{array}{l}\text { Typology and } \\
\text { construction }\end{array}$ & $\begin{array}{l}\text { Converted, 3-storey, } \\
\text { partly pitched/partly flat } \\
\text { roof, brick built }\end{array}$ & $\begin{array}{l}\text { Purpose built, } 5 \text {-storey } \\
\text { modern building, flat } \\
\text { roof, block and beam } \\
\text { built }\end{array}$ \\
\hline $\begin{array}{l}\text { Ventilation and/or } \\
\text { cooling scheme }\end{array}$ & Natural ventilation & Natural ventilation \\
\hline $\begin{array}{l}\text { Single or multi-aspect } \\
\text { bedrooms }\end{array}$ & Single & Single \\
\hline \multirow{2}{*}{$\begin{array}{l}\text { Approximate U-values } \\
\text { (based on age) }\end{array}$} & Wall: 2.15 & Wall: 0.35 \\
\hline & $\begin{array}{l}\text { Ground Floor: } 1.5 \\
\text { Roof: } 2.0\end{array}$ & $\begin{array}{l}\text { Ground Floor: } 0.25 \\
\text { Roof: } 0.20\end{array}$ \\
\hline $\begin{array}{l}\text { Exceptional design } \\
\text { standards or } \\
\text { certification }\end{array}$ & Listed building (Grade II) & $\mathrm{N} / \mathrm{A}$ \\
\hline
\end{tabular}

By comparison, monitored indoor temperatures in VI only reached as high as $32.5{ }^{\circ} \mathrm{C}$ in bedroom VIB2-4th-SW and $31.2{ }^{\circ} \mathrm{C}$ in lounge VIL2-2nd-NE (more than $2{ }^{\circ} \mathrm{C}$ lower than the peak temperatures in PA). Temperatures in the monitored spaces remained in the $24-29^{\circ} \mathrm{C}$ range for the majority of the time, with an overall interquartile range of $25.3-27.7^{\circ} \mathrm{C}$ for all monitored spaces during the entire monitored period. Indoor temperatures did not fall below $21^{\circ} \mathrm{C}$ in any of the monitored spaces, even overnight.

The distribution of indoor temperatures in monitored locations are given in Fig. 5, with the office and lounges showing results for occupied hours and bedrooms showing both day and night results. Of PA's three lounges, PAL1-1st-S stands out as being the warmest by far - median temperature at more than $2{ }^{\circ} \mathrm{C}$ warmer than the other two lounges. Its large south-facing sash windows allowed great solar gains, and it did not have PAL2-G-N's benefit of being north facing nor PAL3-G-S's benefits of shading from tress and being next to the main entrance, allowing significantly more cross-ventilation. Bedroom PAB3-G-S stands out from the other bedrooms as having significantly lower median temperatures, day and night, and a lower and narrow IQR. This room also benefitted from being on the ground floor, and had shade from nearby trees from the early afternoon into the evening.

In VI, the office VIO1-G-int stood out as having a much lower distribution of temperatures compared to the other monitored locations, with $87 \%$ of readings during working hours being between 22 and $26^{\circ} \mathrm{C}$. As with the bedrooms in PA, the day and night temperature distributions in were very similar, but with nighttime temperatures being slightly higher than those during the day.
Plots of the average diurnal temperature profiles for each location type (Fig. 6) showed that in both care homes, the office and lounge temperatures rose during the day and fell overnight in response to the rising and falling of outdoor temperatures. Office and lounge lines ran almost parallel with lounges an average of $0.9{ }^{\circ} \mathrm{C}$ warmer in PA and $2.3^{\circ} \mathrm{C}$ warmer in VI. Bedroom temperatures in both care homes followed a different trend, changing much less throughout the day and remaining high overnight.

\subsection{Current risk of overheating}

Overheating analysis using the static criteria revealed that all of the monitored locations within both care homes exceeded the $28^{\circ} \mathrm{C}$ or $26^{\circ} \mathrm{C}$ thresholds for at least $1 \%$ of occupied hours (Fig. 7 and Table 9). In PA, lounge PAL1-1st-S, with the disadvantage of being on the 1 st floor and south facing, was over $28{ }^{\circ} \mathrm{C}$ for $18.5 \%$ of occupied hours, compared to only $1.6 \%$ of occupied hours in the north-facing ground floor lounge PAL2-G-N. Internal ground floor office VIO1-G-int came closest to passing this threshold, exceeding $28{ }^{\circ} \mathrm{C}$ for only $1.5 \%$ of occupied hours. Of the communal areas, VIL2-2nd-NE exceeded $28{ }^{\circ} \mathrm{C}$ for the longest $-29.1 \%$ of occupied hours, despite having the same north-east orientation as VIL1$1 \mathrm{st}-\mathrm{NE}$, directly below. Although being on a lower floor may have helped, VIL1-1st-NE's main advantage was having two pairs of doors which opened out onto the first floor 'garden' area, allowing significantly more cross-ventilation - when the residents did not complain of the 'draught' and ask for the doors to be closed.

All of the monitored bedrooms failed the static criteria. Three of PA's five monitored bedrooms (PAB2-2nd-S, PAB4-2nd-E and PAB5-2nd-S) exceeded the $26{ }^{\circ} \mathrm{C}$ threshold for more than $50 \%$ of the monitored hours. Notably, these three bedrooms were all on the 2nd (top) floor. Both VI's monitored bedrooms failed the static overheating criteria with significantly more day and night hours over $26^{\circ} \mathrm{C}$ than any of the monitored PA bedrooms. Bedroom VIB2-4th-SW spent almost $90 \%$ of day and night hours above $26{ }^{\circ} \mathrm{C}$, the higher floor and orientation both being a disadvantage when trying to prevent high temperatures.

Public Health England's threshold temperature of $26^{\circ} \mathrm{C}$ was exceeded for $70.1 \%$ of hours in lounge PAL1-1st-S (Table 10). VI's two lounges exceeded $26^{\circ} \mathrm{C}$ for $69-88 \%$ of occupied hours. The two locations which exceeded $26^{\circ} \mathrm{C}$ the least were the two ground floor lounges PAL2-G-N and PAL3-G-S. (Note: this temperature threshold was the same as CIBSE Guide A's for bedrooms).

Dynamic overheating metric CIBSE TM52 had threshold comfort temperatures $\left(\mathrm{T}_{\mathrm{acf}}\right)$ which varied according to the rolling mean of daily average outdoor temperatures. Consequently, following warmer periods of weather $\mathrm{T}_{\mathrm{acf}}$ tended to be higher, but was generally within the $26-28{ }^{\circ} \mathrm{C}$ range. With regards to TM52's first criterion failed if at least $3 \%$ of occupied hours are at least $1{ }^{\circ} \mathrm{C}$ above $\mathrm{T}_{\mathrm{acf}}-$ all monitored space except VIO1-G-int failed (Fig. 8 and Table 11). Bedroom PAB3-G-S failed this criterion for slightly less than $3 \%$ of nighttime hours, but for $7.6 \%$ of daytime hours.

In the bedrooms, an interesting dichotomy appeared between daytime and night-time overheating according to this criterion 1: Five of the seven monitored bedrooms failed for a higher proportion of nighttime hours than daytime hours. This concurs with the monitored temperature profiles, which saw the same five bedrooms experience slightly higher temperatures overnight than during the day. The bedroom which failed criterion 1 the least (i.e. spent the fewest amount of time at least $1{ }^{\circ} \mathrm{C}$ above $T_{\text {acf }}$ ) was PAB3-G-S, which received a good deal of shading from outside during the day and kept the window open at night.

Dynamic criterion 2 - daily weighted exceedance greater than 6 - was failed in all fourteen monitored spaces (Table 12). The worst offenders were the lounges PAL1-1st-S (38 days) and VIL2-2nd-NE 

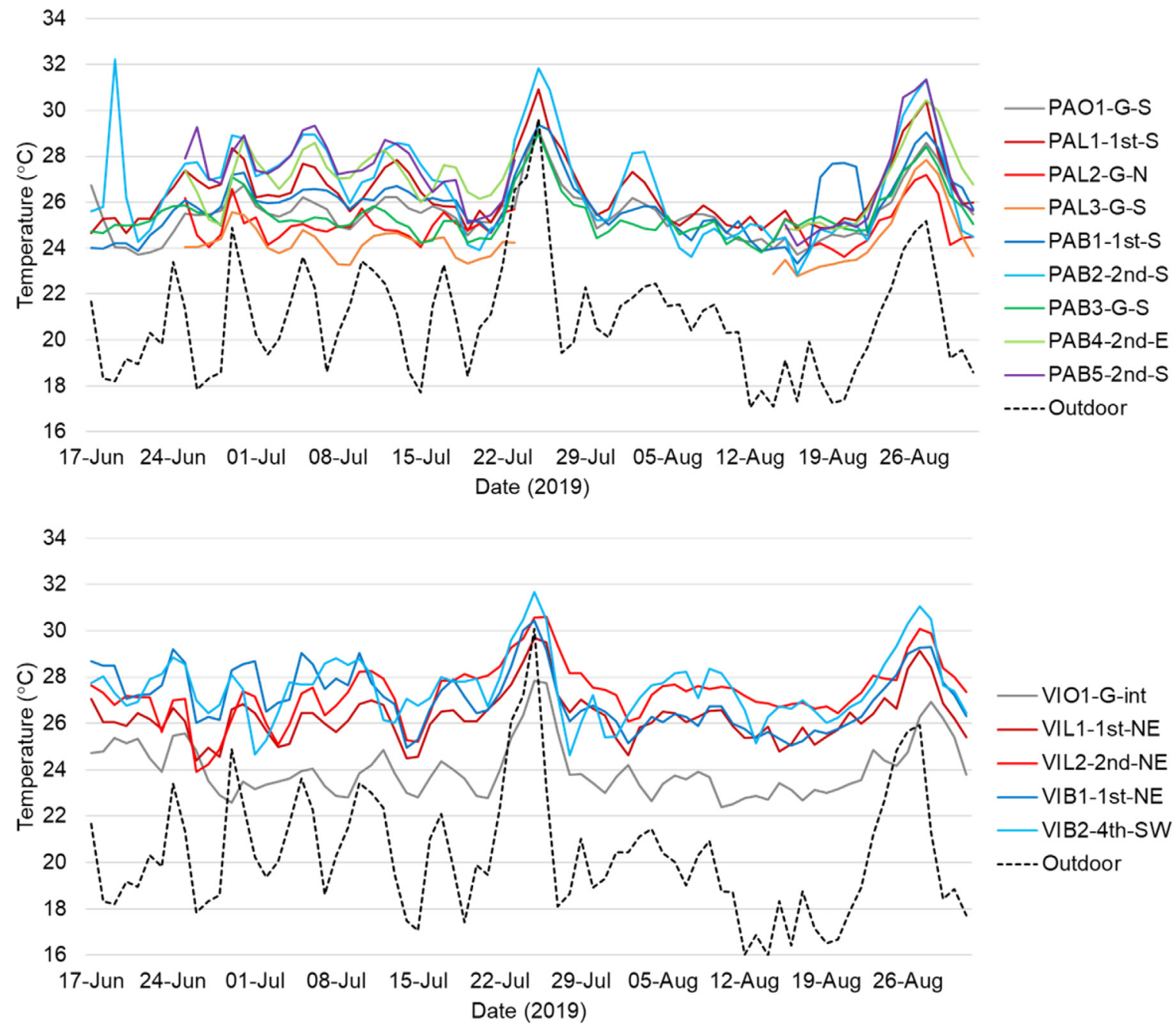

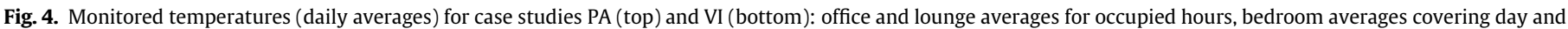
night.

Table 8

Descriptive statistics for monitored locations in PA and VI.

\begin{tabular}{|c|c|c|c|c|c|c|c|c|}
\hline Care home & Location type & Room & Hours & $\mathrm{N}$ & Mean $\left({ }^{\circ} \mathrm{C}\right)$ & Median $\left({ }^{\circ} \mathrm{C}\right)$ & $\operatorname{Min}\left({ }^{\circ} \mathrm{C}\right)$ & $\operatorname{Max}\left({ }^{\circ} \mathrm{C}\right)$ \\
\hline \multirow[t]{15}{*}{ PA } & Office & PAO1-G-S & Occupied & 8098 & 25.9 & 25.8 & 21.8 & 31.9 \\
\hline & Lounges & PAL1-1st-S & & 11,808 & 26.9 & 26.8 & 22.5 & 33.8 \\
\hline & & PAL2-G-N & & 3534 & 25.0 & 24.8 & 23.1 & 28.5 \\
\hline & & PAL3-G-S & & 3534 & 24.8 & 24.5 & 22.2 & 30.1 \\
\hline & Bedroom & PAB1-1st-S & Day & 13,620 & 25.9 & 25.8 & 22.4 & 30.7 \\
\hline & & & Night & 8124 & 26.0 & 26.0 & 23.2 & 30.2 \\
\hline & & PAB2-2nd-S & Day & 13,620 & 26.5 & 26.5 & 20.4 & 34.7 \\
\hline & & & Night & 8124 & 27.0 & 27.0 & 22.5 & 33.4 \\
\hline & & PAB3-G-S & Day & 13,620 & 25.5 & 25.3 & 21.8 & 32.1 \\
\hline & & & Night & 8124 & 25.4 & 25.2 & 23.0 & 29.9 \\
\hline & & PAB4-2nd-E & Day & 4084 & 27.0 & 27.1 & 24.2 & 31.2 \\
\hline & & & Night & 2455 & 27.0 & 27.1 & 24.3 & 31.1 \\
\hline & & PAB5-2nd-S & Day & 4083 & 27.0 & 27.1 & 21.3 & 33.7 \\
\hline & & & Night & 2457 & 27.5 & 27.5 & 23.4 & 32.1 \\
\hline & Outdoor & & All & 21,744 & 20.9 & 20.6 & 11.8 & 35.1 \\
\hline \multirow[t]{8}{*}{ VI } & Office & VIO1-G-int & Occupied & 8208 & 24.2 & 24 & 21.7 & 30.2 \\
\hline & Lounge & VIL1-1st-NE & & 11,856 & 26.5 & 26.5 & 23.0 & 31.4 \\
\hline & & VIL2-2nd-NE & & 11,856 & 27.5 & 27.6 & 22.3 & 32.1 \\
\hline & Bedrooms & VIB1-1st-NE & Day & 13,679 & 27.0 & 26.8 & 20.6 & 31.2 \\
\hline & & & Night & 8208 & 27.2 & 26.9 & 23.0 & 31.5 \\
\hline & & VIB2-4th-SW & Day & 13,680 & 27.5 & 27.3 & 22.8 & 32.5 \\
\hline & & & Night & 8208 & 27.5 & 27.4 & 23.2 & 32.4 \\
\hline & Outdoor & & All & 14,493 & 20.1 & 19.4 & 11.4 & 38.0 \\
\hline
\end{tabular}



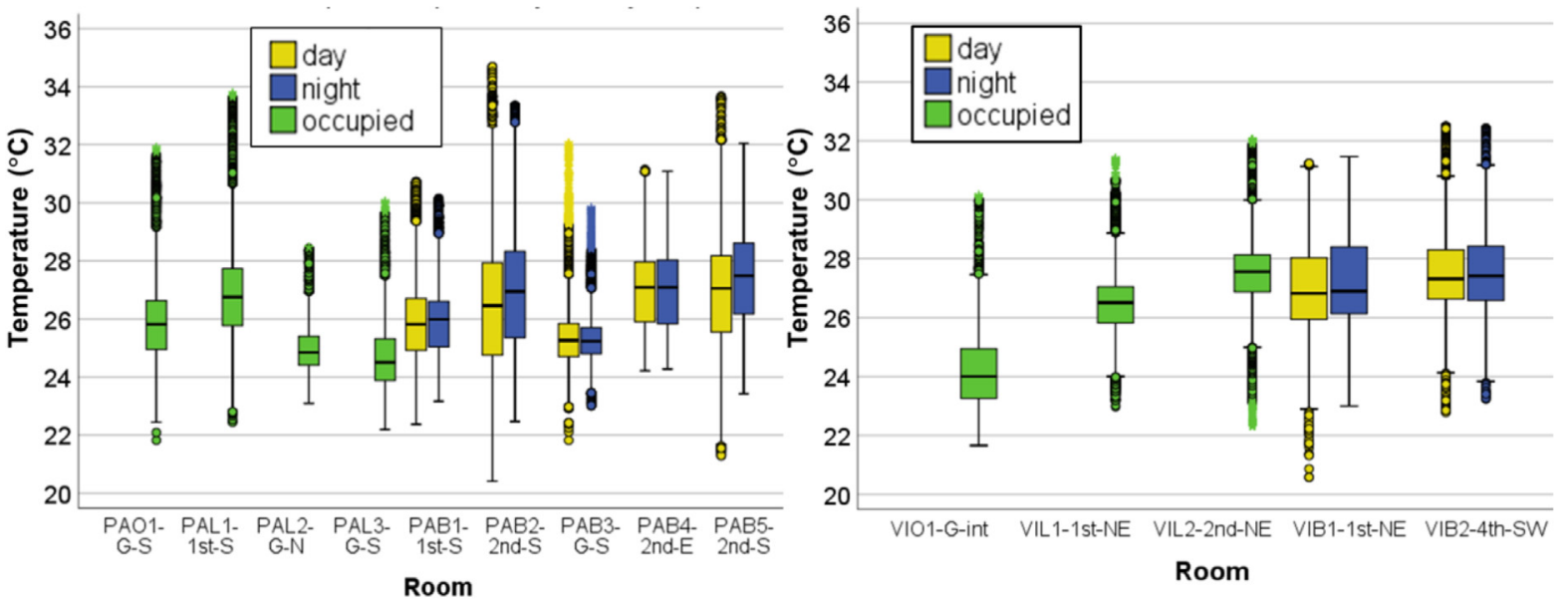

Fig. 5. Boxplot showing distribution of temperatures in selected PA (left) and VI (right) locations.
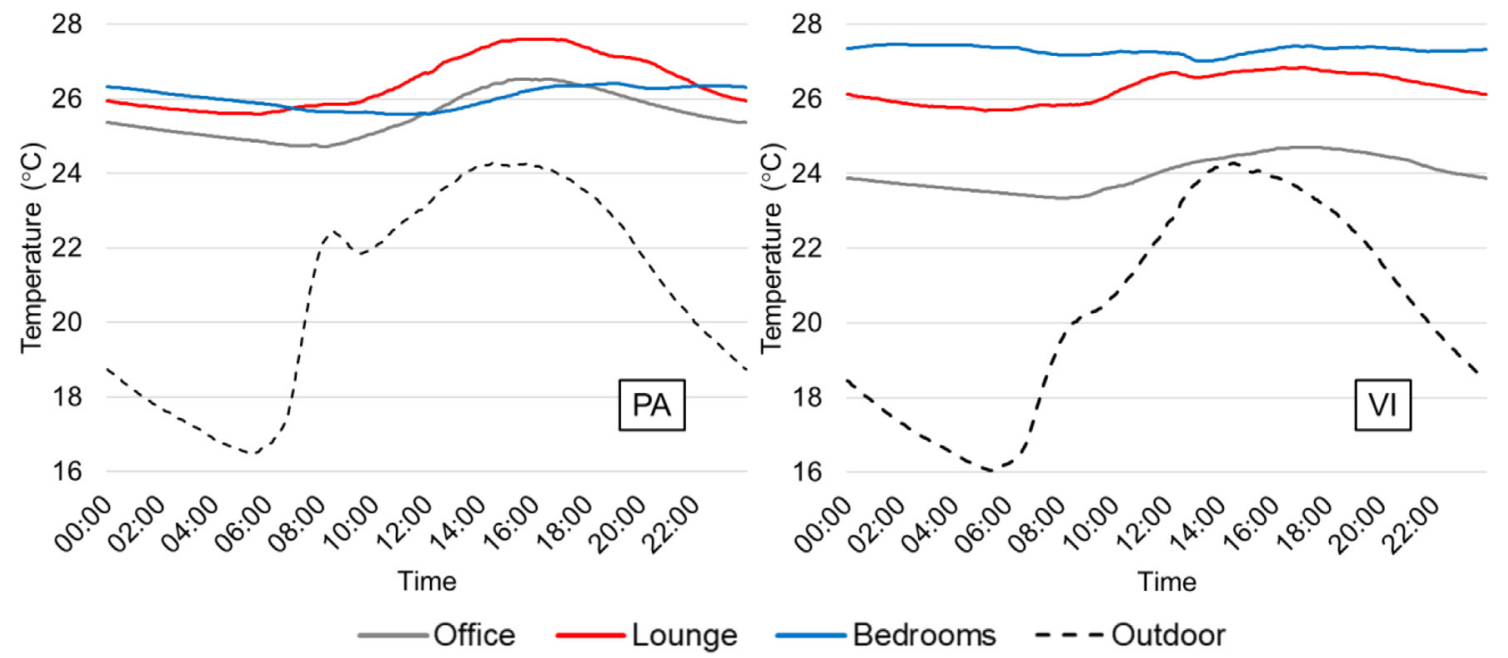

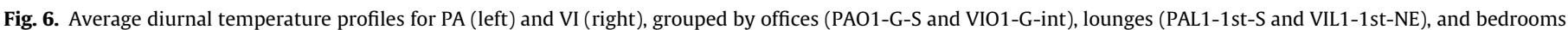
(averages of PAB1-1st-S, PAB2-2nd-S and PAB3-G-S, and of VIB1-1st-NE and VIB2-4th-SW).

(58 days), and the bedrooms PAB2-2nd-S (30 days), VIB1-1st-NE (48 days) and VIB2-4th-SW (59 days).

The third criterion for dynamic overheating was met in ten monitored spaces. Ground floor office VIO1-G-int and ground floor lounges PAL2-G-N and PAL3-G-S did not fail this criterion. The only bedroom not to fail was PAB1-1st-S. Monitored second-floor bedrooms in PA exceeded $\mathrm{T}_{\text {acf }}$ by $6.5^{\circ} \mathrm{C}$ and $7.4{ }^{\circ} \mathrm{C}$, more than any other monitored location other than PA's first floor lounge PAL1-1st-S $\left(6.6^{\circ} \mathrm{C}\right)$.

In summary, thirteen of the fourteen monitored spaces fail at least two of the three TM52 criteria. The only space not to fail was ground floor internal office VIO1-G-int (Table 13). Ground floor spaces were less likely to fail criterion 3 than spaces on other floors.

The fourth overheating metric, TM59, combined static (fixed threshold temperature) criteria and dynamic (variable) overheating criteria. Criterion A, as with CIBSE TM52's Criterion 1, was failed office PAO1-G-S and lounges PAL1-1st-S, VIL11st-NE and VIL2-2nd-NE. All monitored bedrooms failed during daytime hours, PAB3-G-S the only bedroom to not fail during nighttime hours (Table 14). Criterion $\mathrm{B}$, only applicable to bedrooms at night, was failed by all bedrooms, being over $26^{\circ} \mathrm{C}$ for between 124 and 588 of the monitored 675 night-time hours - the maximum allowed being $33 \mathrm{~h}$. Criterion C's fixed-temperature threshold of $26^{\circ} \mathrm{C}$ exceeded for at least $3 \%$ of occupied hours in all but three locations - lounges PAL2G-N and PAL3-G-S and office VIO1-G-int. Although bedroom PAB3-G-S had fewer than 164 night-time hours over $26^{\circ} \mathrm{C}$, during the day it had nearly $229 \mathrm{~h}$ over $26^{\circ} \mathrm{C}$, far more than the maximum $99 \mathrm{~h}$ allowed. Compared to the lounges and bedrooms of PA, those in VI failed criterion C for many more hours during the monitored period. Since a location had to fail only one criterion to fail the whole metric, eleven of the monitored spaces failed TM59. Those which passed were office VIO1-G-int and lounges PAL2-G-N and PAL2-G-S - notably all ground floor locations.

A summary of the four overheating metrics shows that all monitored locations failed at least two of the four (Table 15). All seven monitored bedrooms failed all four metrics. The two fixedtemperature threshold metrics, CIBSE Guide A and PHE, found overheating in all monitored locations. CIBSE TM59 allowed more locations to pass than any other metric, but with the caveat that its thresholds to fail were based on a full non-heating season or year whereas monitoring data were only available for 76 days and were more data available, these locations may not have fared so well. 

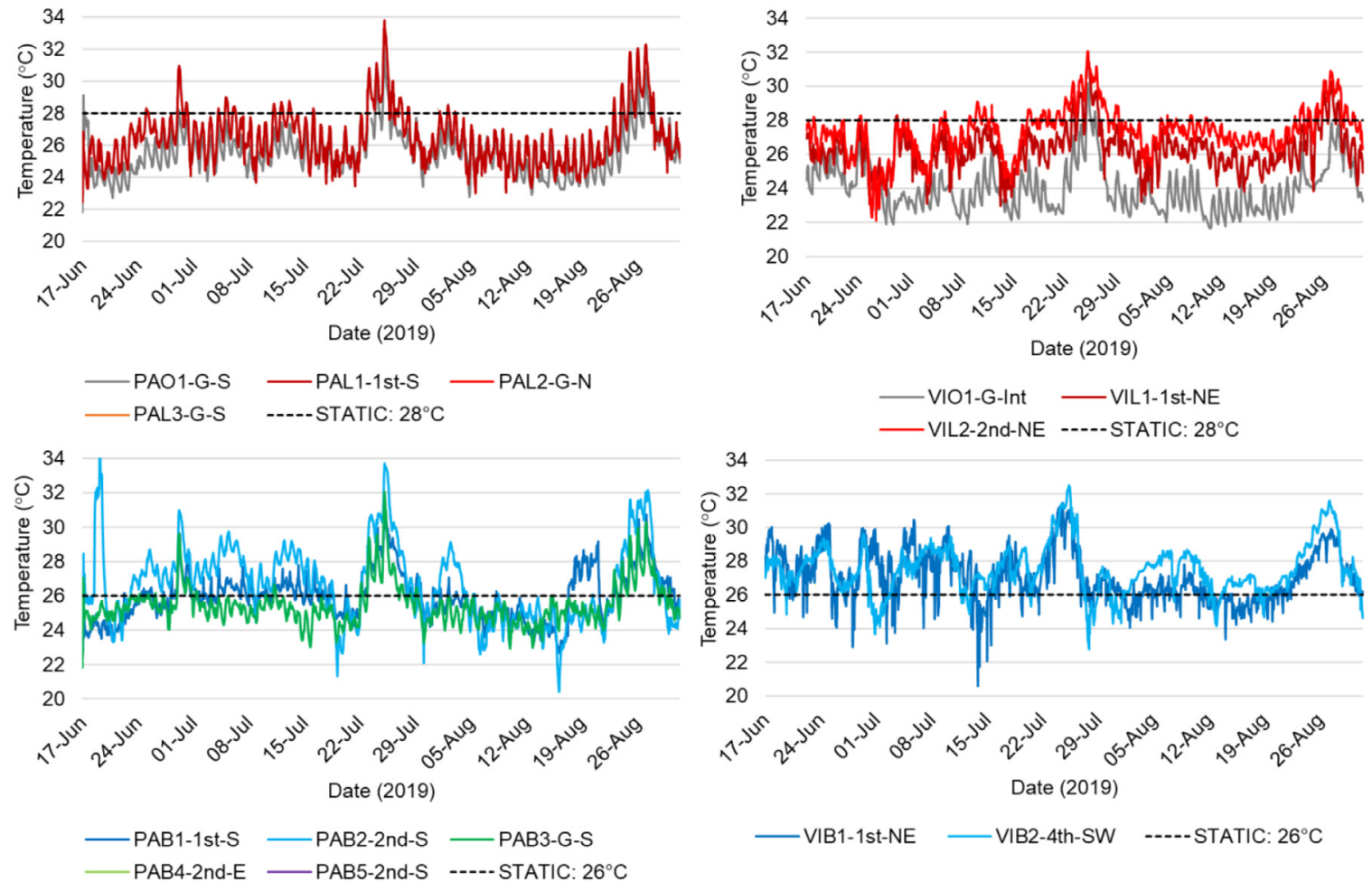

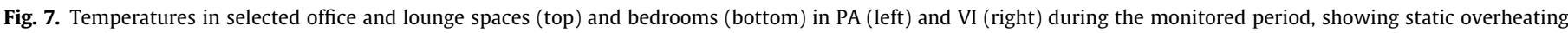
threshold temperature.

Table 9

Percentage of occupied/day/night hours over threshold temperatures in monitored locations.

\begin{tabular}{|c|c|c|c|c|c|}
\hline Care home & Location type & Room & Percent of occupied hours over $28^{\circ} \mathrm{C}$ & Percent of daytime hours over $26^{\circ} \mathrm{C}$ & Percent of night-time hours over $26^{\circ} \mathrm{C}$ \\
\hline \multirow[t]{9}{*}{ PA } & Office & PAO1-G-S & 7.5 & & \\
\hline & Lounge & PAL1-1st-S & 18.5 & & \\
\hline & & PAL2-G-N & 1.6 & & \\
\hline & & PAL3-G-S & 3.3 & & \\
\hline & Bedroom & PAB1-1st-S & & 40.4 & 47.9 \\
\hline & & PAB2-2nd-S & & 49.3 & 54.5 \\
\hline & & PAB3-G-S & & 17.8 & 16.0 \\
\hline & & PAB4-2nd -E & & 59.8 & 59.3 \\
\hline & & PAB5-2nd $-S$ & & 56.3 & 63.2 \\
\hline \multirow[t]{5}{*}{ VI } & Office & VIO1-G-int & 1.5 & & \\
\hline & Lounge & VIL1-1st-NE & 9.9 & & \\
\hline & & VIL2-2nd -NE & 29.1 & & \\
\hline & Bedroom & VIB1-1st-NE & & 72.4 & 78.7 \\
\hline & & VIB2-4th-SW & & 88.8 & 86.2 \\
\hline
\end{tabular}

Table 10

Percentage of occupied hours temperatures exceeded the $26^{\circ} \mathrm{C}$ threshold for PHE's overheating criterion in offices and lounges in PA and VI.

\begin{tabular}{llll}
\hline $\begin{array}{l}\text { Care } \\
\text { home }\end{array}$ & $\begin{array}{l}\text { Location } \\
\text { type }\end{array}$ & Room & $\begin{array}{l}\text { Percent of occupied hours over } \\
26^{\circ} \mathrm{C}\end{array}$ \\
\hline PA & Office & PAO1-G-S & 43.9 \\
& Lounge & PAL1-1st-S & 70.1 \\
& & PAL2-G-N & 14.0 \\
& & PAL3-G-S & 13.6 \\
VI & Office & VIO1-G-int & 10.7 \\
& Lounge & VIL1-1st-NE & 69.1 \\
& & VIL2-2nd - & 88.2 \\
& & NE \\
\hline
\end{tabular}

\subsection{Thermal simulation}

\subsubsection{Future risk of overheating}

For the thermal simulations, a sample office (PAO1-G-S and VIO1-G-int), lounge (PAO1-1st-S and VIO1-1st-S) and bedroom (PAB2-2nd-S and VIB1-1st-NE) were used. Using the projected climate data for 2080 , simulations were run for a five-day heatwave period. Average temperatures in all of the locations were found to be greater than $32{ }^{\circ} \mathrm{C}$, reaching as high as $36{ }^{\circ} \mathrm{C}$ in VIB1-1st-NE (Fig. 9 and Table 16), with maximum predicted temperatures between 35.8 and $39.2{ }^{\circ} \mathrm{C}$. Even minimum predicted temperatures exceeded the CIBSE Guide A static thresholds of $28^{\circ} \mathrm{C}$ (offices and lounges) and $26^{\circ} \mathrm{C}$ (bedrooms). 

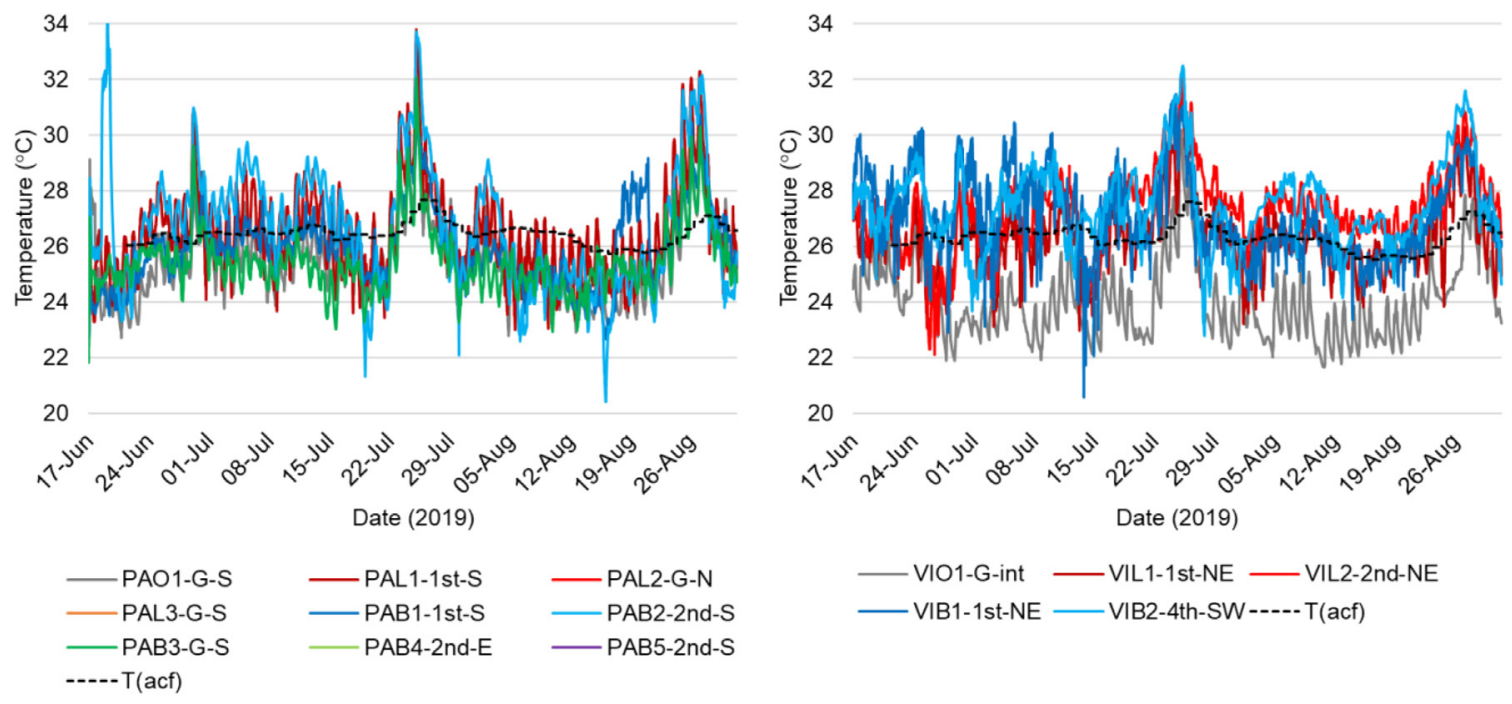

Fig. 8. Temperatures in selected offices, lounges and bedrooms in PA (left) and VI (right), with adaptive threshold comfort temperatures shown.

Table 11

Percentage of occupied/day/night temperatures exceeded the threshold comfort temperature by at least $1^{\circ} \mathrm{C}$ in offices, lounges and bedrooms in PA and VI.

\begin{tabular}{|c|c|c|c|c|c|}
\hline \multirow[t]{2}{*}{ Care home } & \multirow[t]{2}{*}{ Location type } & \multirow[t]{2}{*}{ Room } & \multicolumn{3}{|c|}{ Percent of hours $>=1^{\circ} \mathrm{C}$ above threshold comfort temperature } \\
\hline & & & Occupied & Daytime & Night-time \\
\hline \multirow[t]{9}{*}{ PA } & Office & PAO1-G-S & 9.4 & & \\
\hline & Lounge & PAL1-1st-S & 32.3 & & \\
\hline & & PAL2-G-N & 4.0 & & \\
\hline & & PAL3-G-S & 5.5 & & \\
\hline & Bedroom & PAB1-1st-S & & 16.0 & 13.4 \\
\hline & & PAB2-2nd-S & & 33.2 & 41.2 \\
\hline & & PAB3-G-S & & 7.6 & 3.0 \\
\hline & & PAB4-2nd -E & & 37.4 & 40.4 \\
\hline & & PAB5-2nd -S & & 41.0 & 49.2 \\
\hline \multirow[t]{5}{*}{ VI } & Office & VIO1-G-int & 1.0 & & \\
\hline & Lounge & VIL1-1st-NE & 18.7 & & \\
\hline & & VIL2-2nd -NE & 65.1 & & \\
\hline & Bedroom & VIB1-1st-NE & & 36.3 & 38.4 \\
\hline & & VIB2-4th-SW & & 54.8 & 58.0 \\
\hline
\end{tabular}

Again, considering a simulated five-day heatwave period in 2080 , boxplots showing the projected temperature ranges in the sample offices, lounges and bedrooms revealed the majority of temperatures to be in the $30-36^{\circ} \mathrm{C}$ range in PA and $31-39^{\circ} \mathrm{C}$ range in VI (Fig. 10). The distribution of temperatures was clearly higher and had wider ranges in VI than in PA. Both care homes saw a similar decrease in temperatures over the five day period from the hottest day (22nd Jul) to the least hot day (26th Jul) (Fig. 11).

Diurnal temperature variations averaged over the five-day heatwave period showed both care homes having their least hot periods between 07:00 and 09:00. From then on, indoor temperatures rose in both care homes (Fig. 12). Interestingly, indoor temperatures in PA rose more gradually, not reaching their peak until around 16:00, and beginning to decrease again from around 20:00. By contrast, in care home VI indoor temperatures increased more rapidly throughout the morning, reaching their peak earlier in the day, from around 13:00. As with PA, VI's indoor temperatures remained high until around 20:00, meaning they were at their peak for significantly longer than in PA.

It was clear that projected temperatures for 2080 (future climate) followed a similar trend with the monitored temperature data for 2019 (current climate). The risk of overheating increased considerably in the future compared to the current climatic scenarios; almost all projected temperature ranges during the five-day heatwave period failed to meet the static criteria in both care homes. Temperature averages for office, lounge and bedroom in PA and VI ranged from 31.5 to $35.9{ }^{\circ} \mathrm{C}, 3-7^{\circ} \mathrm{C}$ higher than the threshold of $28^{\circ} \mathrm{C}$, while no temperatures fell below $27^{\circ} \mathrm{C}$. Temperature averages and ranges were notably higher in the newer care home (VI) compared to the older one (PA). Although office average temperatures and typical ranges were closely matched (in the $31-34{ }^{\circ} \mathrm{C}$ range), average temperature in VI's lounge exceeded that in PA's lounge by almost $3^{\circ} \mathrm{C}$, while the typical temperature range was $32-36{ }^{\circ} \mathrm{C}(\mathrm{VI})$ compared to $30-34{ }^{\circ} \mathrm{C}(\mathrm{PA})$. Similarly, the average temperature in VI's bedroom was more than $2{ }^{\circ} \mathrm{C}$ higher than in PA's bedroom.

\subsubsection{Modelling of passive strategies}

To avoid the risk of active cooling to bring down the indoor temperatures in current and future climate, six different building adaptation scenarios were investigated as outlined in Table 6. The simulations considered the current climate (using 2019 weather data) and future climate (2080 simulated data). With projected increases in global temperature, the cooling load needs in both care homes increased greatly in the future climate (Fig. 13): between 5 and 12 times in PA, and 2 and 22 times in VI.

Scenario 6 - using a combination of hard adaptations (daytime AC, external shading and reflective surfaces) and soft adaptations 
Table 12

Descriptive statistics for criteria 2 and 3 in monitored PA and VI spaces.

\begin{tabular}{|c|c|c|c|c|c|}
\hline $\begin{array}{l}\text { Care } \\
\text { home }\end{array}$ & $\begin{array}{l}\text { Location } \\
\text { type }\end{array}$ & Room & $\begin{array}{l}\text { Criterion 2: No. of days when } \mathrm{W}_{\mathrm{e}} \text { greater } \\
\text { than } 6 \text { h per day (no. of monitored days) }\end{array}$ & $\begin{array}{l}\text { Percent of monitored days } \\
\text { when } W_{\mathrm{e}} \text { greater than } 6 \mathrm{~h} \\
\text { per day }\end{array}$ & $\begin{array}{l}\text { Criterion 3: Maximum temperature above } \mathrm{T}_{\text {acf }} \\
\left({ }^{\circ} \mathrm{C}\right) \text { during occupied hours (all hours in } \\
\text { bedrooms) }\end{array}$ \\
\hline \multirow[t]{9}{*}{ PA } & Office & PAO1-G-S & $9(71)$ & 12.7 & 4.7 \\
\hline & \multirow[t]{3}{*}{ Lounge } & PAL1-1st-S & $38(71)$ & 53.5 & 6.6 \\
\hline & & PAL2-G-N & $1(48)$ & 2.1 & 1.9 \\
\hline & & PAL3-G-S & $3(48)$ & 6.3 & 3.2 \\
\hline & \multirow[t]{5}{*}{ Bedroom } & PAB1-1st-S & $16(71)$ & 22.5 & 3.9 \\
\hline & & PAB2-2nd-S & $39(71)$ & 54.9 & 6.5 \\
\hline & & PAB3-G-S & $11(71)$ & 15.5 & 4.8 \\
\hline & & PAB4-2nd -E & 27 (49) & 55.1 & 4.3 \\
\hline & & PAB5-2nd -S & $30(49)$ & 61.2 & 7.4 \\
\hline \multirow[t]{5}{*}{ VI } & Office & VI01-G-int & $1(71)$ & 1.4 & 3.1 \\
\hline & \multirow[t]{2}{*}{ Lounge } & VIL1-1st-NE & $24(71)$ & 33.8 & 4.3 \\
\hline & & VIL2-2nd -NE & $58(71)$ & 81.7 & 4.9 \\
\hline & \multirow[t]{2}{*}{ Bedroom } & VIB1-1st-NE & $48(71)$ & 64.8 & 4.6 \\
\hline & & VIB2-4th-SW & $59(71)$ & 83.1 & 5.4 \\
\hline
\end{tabular}

Table 13

Monitored spaces in PA and VI which failed the CIBSE TM52 dynamic overheating criteria.

\begin{tabular}{|c|c|c|c|c|c|}
\hline Care home & Location type & Room & Criterion 1 & Criterion 2 & Criterion 3 \\
\hline \multirow[t]{9}{*}{ PA } & Office & PA01-G-S & $\times$ & $\times$ & $x$ \\
\hline & Lounge & PAL1-1st-S & $\times$ & $\times$ & $x$ \\
\hline & & PAL2-G-N & $\times$ & $\times$ & \\
\hline & & PAL3-G-S & $\times$ & $\times$ & \\
\hline & Bedroom & PAB1-1st-S & $\times$ & $\times$ & \\
\hline & & PAB2-2nd-S & $\times$ & $\times$ & $\times$ \\
\hline & & PAB3-G-S & $\times$ & $\times$ & $x$ \\
\hline & & PAB4-2nd -E & $\times$ & $\times$ & $\times$ \\
\hline & & PAB5-2nd -S & $\times$ & $\times$ & $\times$ \\
\hline \multirow[t]{5}{*}{ VI } & Office & VIO1-G-int & & $\times$ & \\
\hline & Lounge & VIL1-1st-NE & $\times$ & $\times$ & $x$ \\
\hline & & VIL2-2nd -NE & $\times$ & $\times$ & $\times$ \\
\hline & Bedroom & VIB1-1st-NE & $\times$ & $\times$ & $x$ \\
\hline & & VIB2-4th-SW & $\times$ & $\times$ & $\times$ \\
\hline
\end{tabular}

(nighttime window opening to purge heat) - was found to be the most beneficial for energy consumption in both the current and future climates in both care homes. Interestingly, in the current climate, Scenario 5 - daytime AC and reflective surfaces (both hard adaptations) - had the highest energy consumption in both care homes, whereas in the future scenario, Scenario 2 - using hard adaptation AC during the day and overnight - proved to be the least beneficial for energy consumption. In the current climate, the soft adaptation of nighttime ventilation to purge daytime heat gains (Scenario 3) appeared to be more effective than the use of the hard adaptation of external shading (Scenario 4). However, in the future climate, external shading appeared to be more effective: with higher projected outdoor temperatures, window opening became a less effective method of cooling.

The results from thermal simulation models suggested a high increase in cooling loads by 2080 , for both the old and the new care homes, expected given the significant increase in outdoor temperatures under the future climate scenario. For both care homes and for both present and future climates, S6 (AC combined with ventilation, shading and reflective surfaces) was most effective. The application of high albedo materials on the exterior walls combined with the daily use of AC (S5), and the continuous use of AC (S2), appeared to have the smallest impact on reducing current and future cooling loads.

To understand the generalisability of the findings an indicative uncertainty and sensitivity assessment was undertaken for scenario 6 for current and future climate for the peak summer week.
The factors that were varied were occupancy rates, internal gains (lighting and equipment), operation of windows (opening area and operation schedule), thermal conductivity of envelope thermal mass and location (urban/sheltered and rural/unsheltered). The variation was assessed for half, single or double occupancy rate; for $10 \%$ deviation in other space loads and thermal properties, in line with the typical variations quoted in BS EN 15603-2008 [6]; operation of windows was tested for quarter, half or full opening area and the various operation times of window opening scenarios (always closed, day-time only, night-time only, always open); and geographically tested for urban and rural settings. Resultant uncertainty in cooling load was up to $\pm 21 \%$ standard deviation and sensitivity results showed that the operation of windows, envelope thermal performance and occupancy rate were the most important parameters affecting the cooling loads. Window operations were 2-3 times more influential factor than envelope thermal properties and impact of any other internal gains or location was negligible.

Temperatures within the care homes were simulated using historic 2019 weather data files. In the baseline scenario 1, the three spaces in each home all had average temperatures below CIBSE Guide A's 26 and $28{ }^{\circ} \mathrm{C}$ temperature thresholds (Fig. 14, left). Interestingly, only scenario 3 (daytime $A C$ and nighttime ventilation to purge heat gains) and scenario 6 (daytime AC, nighttime ventilation, external shading and reflective surfaces) were able to produce average temperatures lower than the baseline simulation, the other measures seemingly leading to higher temperatures. 
Table 14

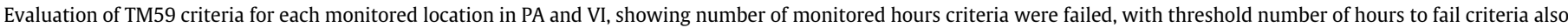
shown.

\begin{tabular}{|c|c|c|c|c|c|c|c|c|c|}
\hline \multirow[t]{2}{*}{ Care home } & \multirow[t]{2}{*}{ Location type } & \multirow[t]{2}{*}{ Room } & \multicolumn{3}{|l|}{ Criterion A } & \multirow[t]{2}{*}{ Criterion B } & \multicolumn{3}{|l|}{ Criterion C } \\
\hline & & & Occupied & Day & Night & & Occupied & Day & Night \\
\hline \multirow[t]{9}{*}{ PA } & Office & PAO1-G-S & 59 & & & & 296 & & \\
\hline & Lounge & PAL1-1st-S & 298 & & & & 687 & & \\
\hline & & PAL2-G-N & 23 & & & & 83 & & \\
\hline & & PAL3-G-S & 33 & & & & 80 & & \\
\hline & Bedroom & PAB1-1st-S & & 170 & 86 & 337 & & 492 & 337 \\
\hline & & PAB2-2nd-S & & 351 & 265 & 422 & & 639 & 422 \\
\hline & & PAB3-G-S & & 81 & 19 & 124 & & 229 & 124 \\
\hline & & PAB4-2nd-E & & 252 & 168 & 306 & & 497 & 306 \\
\hline & & PAB5-2nd-S & & 276 & 204 & 315 & & 468 & 315 \\
\hline \multirow[t]{5}{*}{ VI } & Office & VIO1-G-int & 7 & & & & 72 & & \\
\hline & Lounge & VIL1-1st-NE & 172 & & & & 676 & & \\
\hline & & VIL2-2nd-NE & 598 & & & & 1725 & & \\
\hline & Bedroom & VIB1-1st-NE & & 384 & 248 & 536 & & 1632 & 536 \\
\hline & & VIB2-4th-SW & & 581 & 374 & 588 & & 1002 & 588 \\
\hline \multirow{2}{*}{\multicolumn{3}{|c|}{ Threshold to fail criterion (hours) }} & 42 (offices) & 41 & 69 & 33 & 99 (offices) & 99 & 164 \\
\hline & & & 60 (lounges) & & & & 143 (lounges) & & \\
\hline
\end{tabular}

Table 15

Overheating metrics for each monitored location in PA and VI.

\begin{tabular}{|c|c|c|c|c|c|c|}
\hline Care home & Location type & Room & CIBSE Guide A & PHE & CIBSE TM52 & TM59 \\
\hline \multirow[t]{9}{*}{ PA } & Office & PAO1-G-S & $\times$ & $\times$ & $\times$ & $\times$ \\
\hline & Lounge & PAL1-1st-S & $\times$ & $\times$ & $\times$ & $\times$ \\
\hline & & PAL2-G-N & $\times$ & $x$ & $x$ & \\
\hline & & PAL3-G-S & $\times$ & $\times$ & $\times$ & \\
\hline & Bedroom & PAB1-1st-S & $\times$ & $\times$ & $\times$ & $\times$ \\
\hline & & PAB2-2nd-S & $\times$ & $\times$ & $\times$ & $\times$ \\
\hline & & PAB3-G-S & $\times$ & $\times$ & $\times$ & $\times$ \\
\hline & & PAB4-2nd -E & $\times$ & $\times$ & $\times$ & $\times$ \\
\hline & & PAB5-2nd -S & $\times$ & $\times$ & $\times$ & $\times$ \\
\hline \multirow[t]{5}{*}{ VI } & Office & VIO1-G-int & $\times$ & $\times$ & & \\
\hline & Lounge & VIL1-1st-NE & $\times$ & $\times$ & $\times$ & $\times$ \\
\hline & & VIL2-2nd -NE & $\times$ & $\times$ & $\times$ & $\times$ \\
\hline & Bedroom & VIB1-1st-NE & $\times$ & $x$ & $x$ & $x$ \\
\hline & & VIB2-4th-SW & $\times$ & $\times$ & $\times$ & $\times$ \\
\hline
\end{tabular}

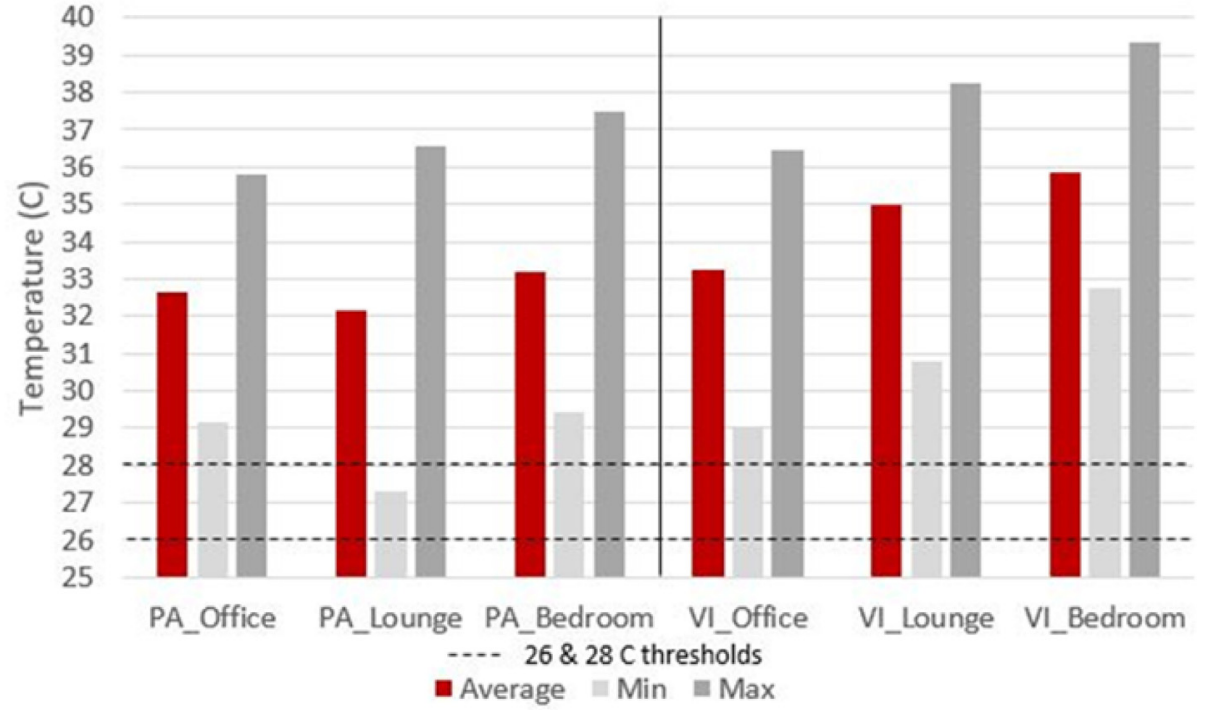

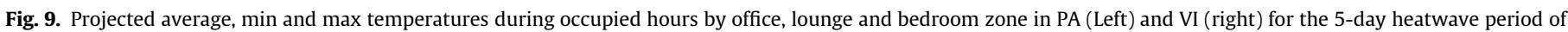
2080. 
Table 16

Descriptive statistics of modelled temperatures in office, lounge and bedroom zones in PA and VI for the five-day heatwave period of 2080.

\begin{tabular}{|c|c|c|c|c|c|c|c|}
\hline \multirow[t]{2}{*}{ Hours } & \multirow[t]{2}{*}{ Modelled Temperatures $\left({ }^{\circ} \mathrm{C}\right)$} & \multicolumn{3}{|l|}{ PA } & \multicolumn{3}{|l|}{ VI } \\
\hline & & Office & Lounge & Bedroom & Office & Lounge & Bedroom \\
\hline \multirow[t]{3}{*}{ All } & Average & 32.01 & 31.46 & 33.23 & 32.70 & 34.06 & 35.89 \\
\hline & Min & 28.16 & 27.18 & 29.40 & 29.07 & 30.34 & 32.73 \\
\hline & Max & 35.82 & 36.54 & 37.48 & 36.47 & 38.23 & 39.33 \\
\hline \multirow[t]{3}{*}{ Occupied Hours } & Average & 32.64 & 32.17 & 33.23 & 33.25 & 34.98 & 35.89 \\
\hline & Min & 29.16 & 27.31 & 29.40 & 29.07 & 30.76 & 32.73 \\
\hline & Max & 35.82 & 36.54 & 37.48 & 36.47 & 38.23 & 39.33 \\
\hline
\end{tabular}
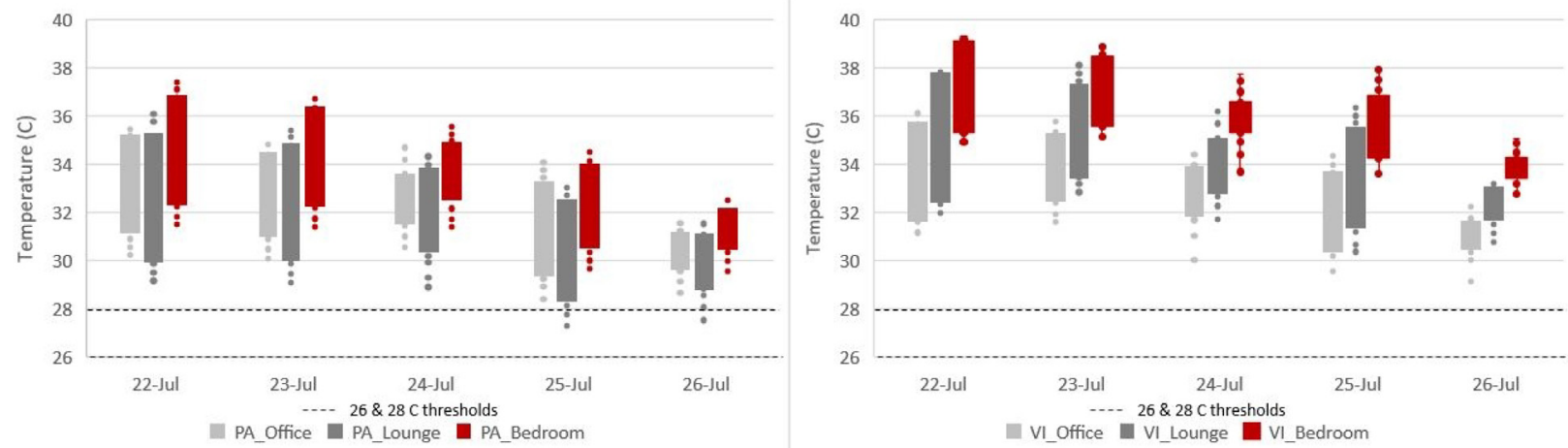

Fig. 10. Projected temperature range by office, lounge and bedroom zone in PA (Left) and VI (right) for the 5-day heatwave period of 2080.
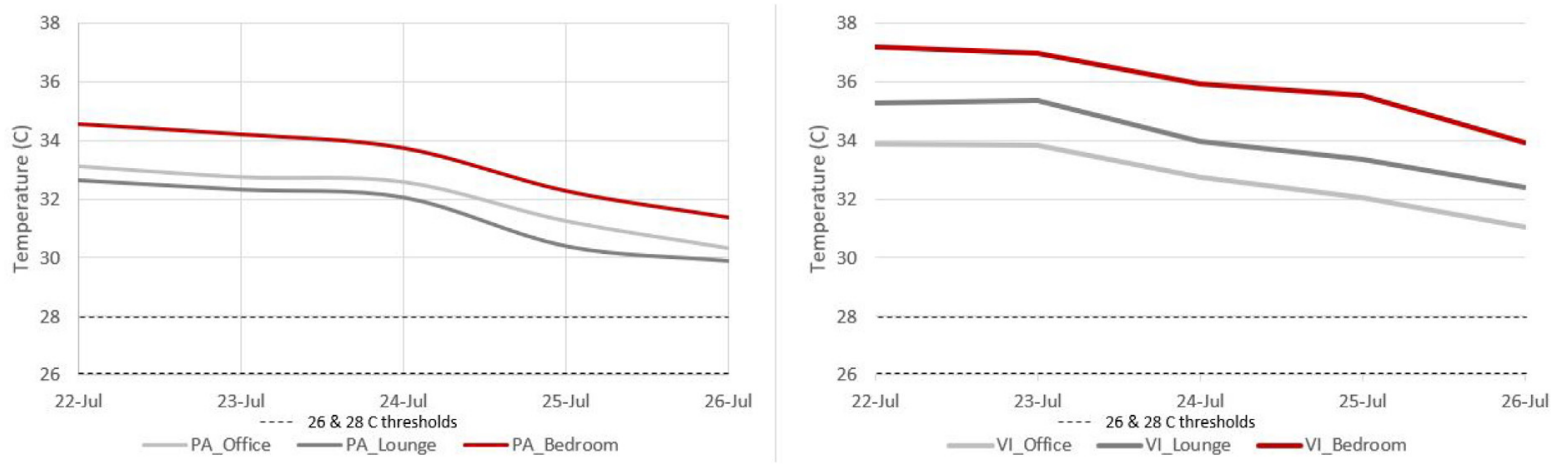

Fig. 11. Projected daily average temperatures of office, lounge and bedroom zones in PA (left) and VI (right) for the 5-day heat wave period of 2080.
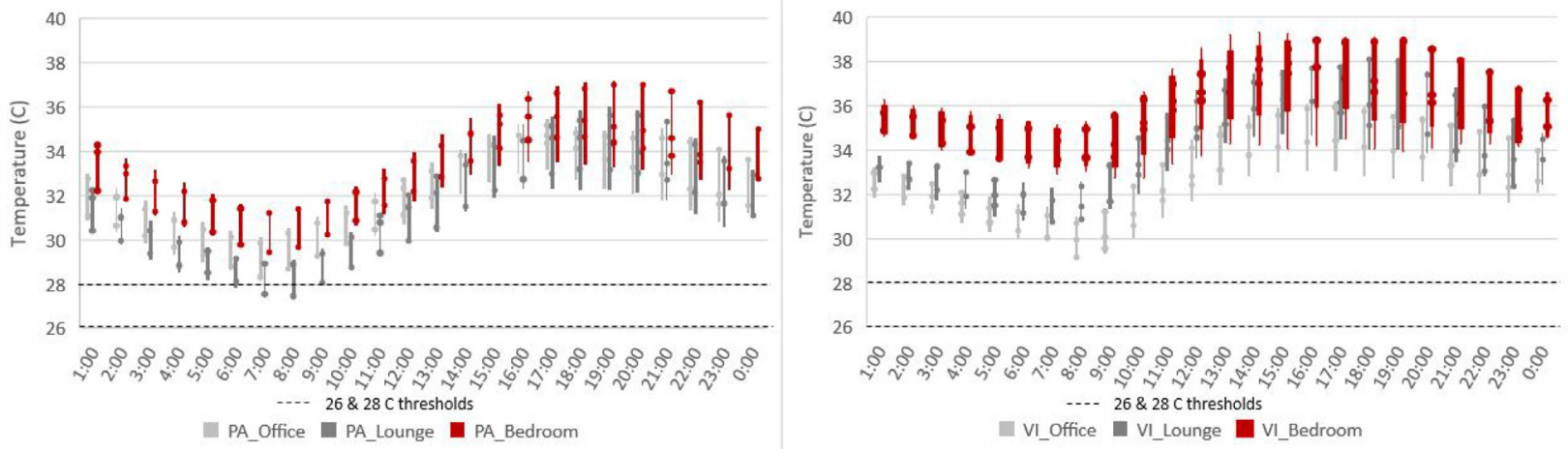

Fig. 12. Projected hourly variations of office, lounge and bedroom zone temperatures in PA (left) and VI (right) for the 5-day heatwave period of 2080. 


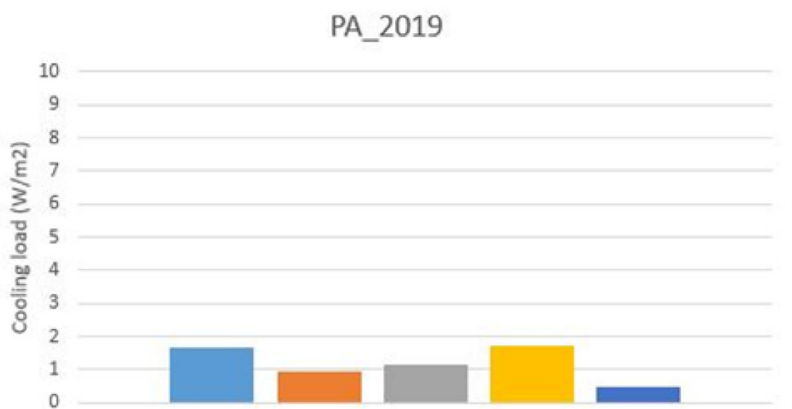

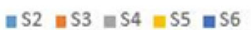

VI_2019

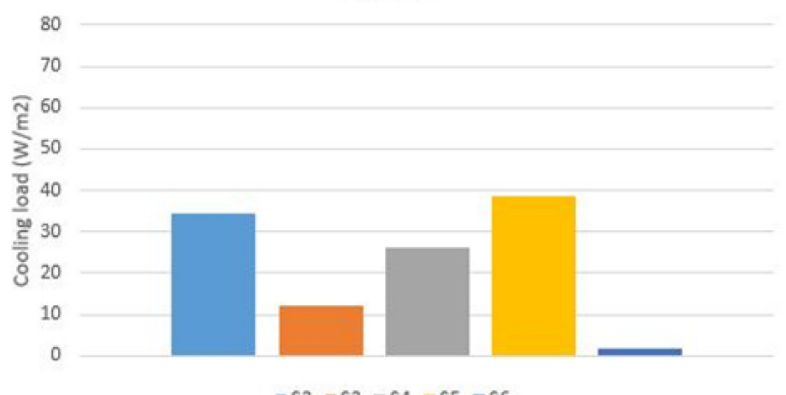

$=\$ 2=\$ 3=\$ 4=\$ 5=\$ 6$
PA_2080

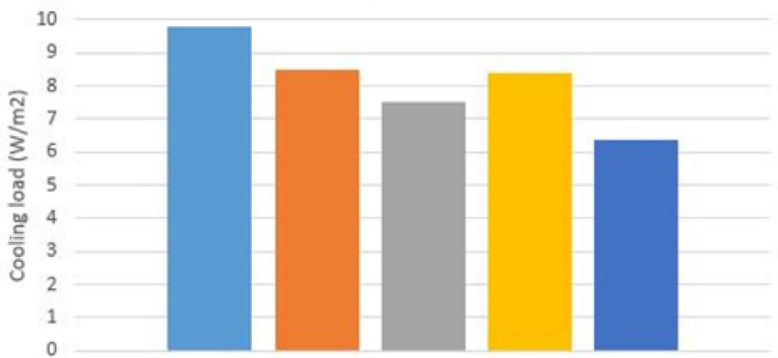

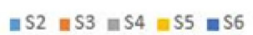

VI_2080

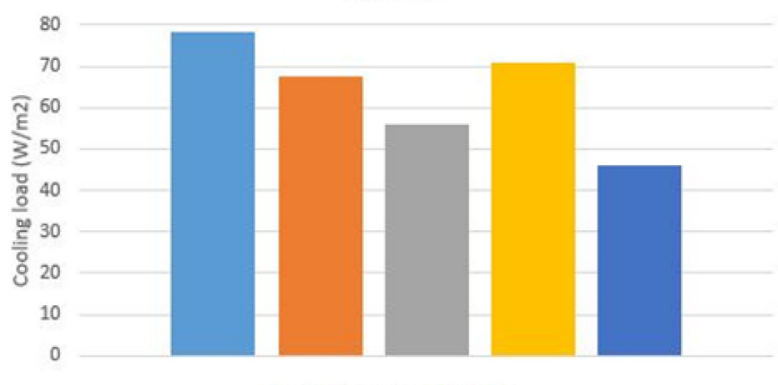

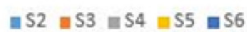

Fig. 13. Modelled building average cooling loads by simulation scenarios in PA (top) and VI (bottom) for the 5-day heatwave period of 2019 and 2080.

PA_2019

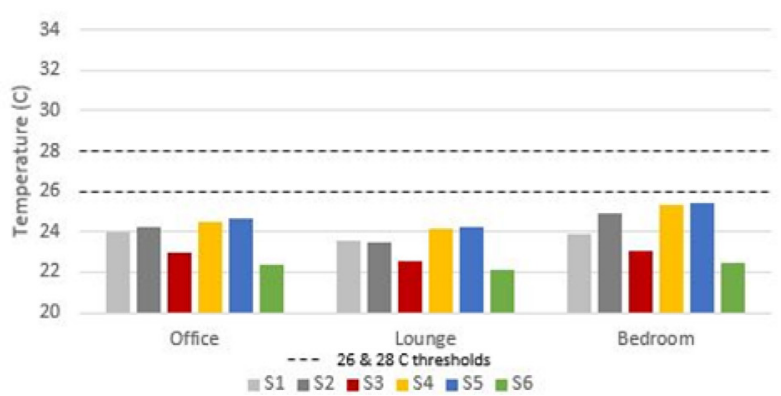

VI 2019

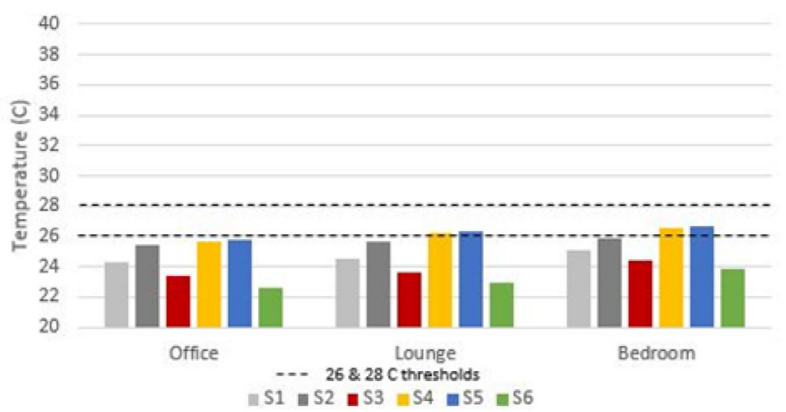

PA_2080
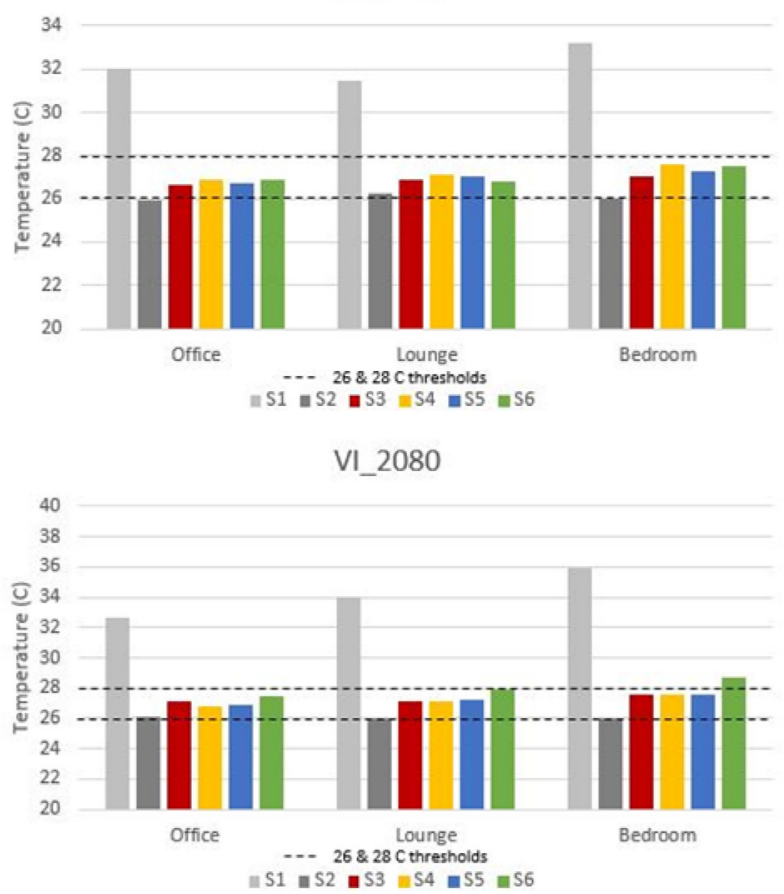

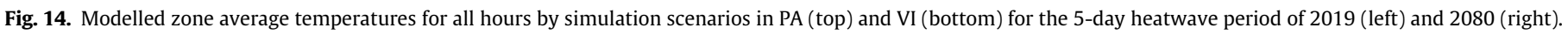

In the 2080 simulations, baseline scenario 1 average temperatures had increased significantly, to between $31^{\circ} \mathrm{C}$ in lounge PAL1-1st-S and $36{ }^{\circ} \mathrm{C}$ In bedroom VIB1-1st-NE (Fig. 14, right). All five scenarios were able to bring temperatures down much lower than these baseline temperatures, and there was less of a difference between the different scenarios in terms of average temperatures they produced compared to the 2019 simulations. In the 2080 simulations, scenario S2 (AC only, day and night) produced the lowest average temperatures all six locations, with S6 the least effective on average, particularly in VI. For bedrooms, although S2 was the only scenario able to keep average temperatures below $26^{\circ} \mathrm{C}$, it was likely that at least $1 \%$ of hours would have 
been above $26^{\circ} \mathrm{C}$, the threshold for overheating according to CIBSE Guide A. Indeed, with average temperatures in the $26-28^{\circ} \mathrm{C}$ range for both offices and lounges, it is exceedingly likely that the $28{ }^{\circ} \mathrm{C}$ threshold would also have been exceeded for more than $1 \%$ of occupied hours regardless of the scenario adopted.

Thermal simulation affirmed that projected indoor temperatures in both care settings remained considerably lower than the 26 and $28{ }^{\circ} \mathrm{C}$ static thresholds under all scenarios, except for VI's bedroom. Under future climatic conditions, all zones in both settings had average temperatures $4-8{ }^{\circ} \mathrm{C}$ above the $28^{\circ} \mathrm{C}$ threshold in baseline scenario S1. Simulations under current climatic conditions found the application of high albedo materials in external walls, combined with external shading, night ventilation and daily use of AC (S6) the most effective scenario in reducing overheating, lowering average temperatures by around $2{ }^{\circ} \mathrm{C}$ compared to baseline S1. Under future climatic conditions, continuous use of AC (S2) was found to be the most effective, bringing average temperatures down by almost $10^{\circ} \mathrm{C}$. Of the other scenarios, the highest temperature reduction was produced by $\mathrm{S} 2$ in the old care home (PA) and S4 in the new (VI).

\section{Discussion}

Continuous monitoring of indoor and outdoor temperature in summer 2019 revealed that overheating was a current risk that was prevalent, prolonged and severe across both care homes. However local differences in the magnitude of indoor temperature were observed in the two care homes buildings due to difference in the size and age of the buildings. Monitored rooms in care home PA reached higher temperatures than those in VI, with peak bedroom temperatures as high as $34.7^{\circ} \mathrm{C}$ (PAB2-2nd-S) compared to $32.5^{\circ} \mathrm{C}$ (VIB2-4th-SW) and peak lounge temperatures as high as $33.8^{\circ} \mathrm{C}$ (PAL1-1st-S) compared to $31.2^{\circ} \mathrm{C}$ (VIL2-2nd-NE).

This is why both buildings remained warm overnight, with indoor temperatures never falling below $20^{\circ} \mathrm{C}$ in PA and $21^{\circ} \mathrm{C}$ in VI. Although temperatures in the monitored offices and lounges fell slightly overnight, diurnal profiles indicated that, with windows and doors closed, the bedrooms temperatures actually increased overnight in both buildings. Nocturnal purging of heat can be one of the simplest, low-cost ways of keeping temperatures in a building within comfortable (and safe) levels during hot summer periods. But with the majority of rooms within both care homes being bedrooms, this becomes extremely challenging. Bedroom doors are routinely closed, both so as to minimise any disturbance to the residents while they sleep and for their safety. Windows are also routinely closed at night in the empty offices and lounges, and also in the occupied bedrooms. Bedrooms were the warmest monitored locations in both care homes.

Interestingly similar trends were observed in both care homes with regards to the four overheating metrics investigated. CIBSE Guide A's static $28^{\circ} \mathrm{C}$ and $26^{\circ} \mathrm{C}$ temperature thresholds for offices/lounges and bedrooms were exceeded for the maximum $1 \%$ of occupied hours in every monitored space. Some rooms came close to staying below the threshold, notably lounges PAL2-G-N (1.6\%) and PAL3-G-S (3.3\%) and office VIO1-G-int (1.5\%). Interestingly these three spaces were all on the ground floors, as was bedroom PAB3-G-S, which exceeded $26^{\circ} \mathrm{C}$ far less often than the other monitored bedrooms. The stricter PHE overheating metric was also failed in all monitored spaces, between 13 and $76 \%$ of occupied/day/night hours in PA's rooms and between 69 and 89\% of occupied/day/night hours in VI's rooms.

The adaptive TM52 metric provided varying temperature thresholds generally somewhere in between the static limits of $26-28{ }^{\circ} \mathrm{C}$, higher following warmer outdoor periods. This allowed one location - VIO1-G-int - to pass the metric, but all other loca- tions still failed, the majority failing all three criteria. Metric TM59 was also failed in the majority of monitored spaces. Despite failing TM52's criterion 1, ground floor lounges PAL2-G-N and PAL3-G-S were not overheating according to TM59 criterion A since monitored data covered less than half of the May-Sept nonheating season considered by this criterion. VI's ground floor office VIO1-G-int also passed TM59. Criterion C's upper limit of $143 \mathrm{~h}$ was exceeded by up to $1580 \mathrm{~h}$ in monitored spaces. It was clear that regardless of the overheating metric applied to the case study care homes, they were found to be overheating in the current climate, particularly in the bedrooms and often at night.

Unsurprisingly the prevalence of overheating became more severe in the projected future climate of 2080 . Over a simulated fiveday summer heatwave period, the selected locations had average indoor temperatures of $32-36^{\circ} \mathrm{C}$, reaching highs of $36-39{ }^{\circ} \mathrm{C}$. Care home VI fared worse in the 2080 scenario with significantly higher indoor temperatures than PA. Diurnal profiles also revealed VI to experience a more rapid rise in indoor temperatures throughout the morning, reaching a peak around three hours earlier than in PA and remaining there until mid-evening. The medium weight construction and lack of external shading likely contributed to VI's poorer performance.

The passive strategies investigated to mitigate against the high indoor temperatures and minimise active cooling highlighted the common pay-off that often occurs between energy intensity cooling load per $\mathrm{m}^{2}-$ and reduction in indoor temperature. The scenario most successful in reducing indoor temperatures was the most energy intense and vice versa. In a future scenario with a decarbonised energy grid and possible localised energy production, energy intensity factor in may be reduced depending upon the timing of energy demand. Given that even the most energyintense scenario 2 - the hard adaptation of using AC around the clock - still resulted in high average indoor temperatures which may well have failed all of the overheating criteria investigated, it is likely that further measures may be necessary in order to bring indoor temperatures down to levels which are safe and comfortable for the residents and staff.

\section{Conclusions}

This research has systematically examined the prevalence, intensity and possible solutions for tackling summertime overheating during the summer of 2019 in two London care homes occupying modern and older buildings. Continuous monitoring of indoor temperature in different spaces of the two care homes along with outdoor temperature allowed detailed analysis of overheating using four distinct metrics. Thermal simulation helped to identify the current and future risk of overheating in a warming climate. The monitoring data was used to calibrate and validate the thermal models, which enabled the testing of passive solutions for avoiding cooling in the care homes under a set of representative climate change scenarios.

Both care homes were found to experience overheating regardless of the metrics used. Fixed-temperature-threshold metrics - CIBSE Guide A and PHE - identified all monitored locations to be overheating. Variable-temperature-threshold metrics TM52 and TM59 - found the majority of monitored locations to be overheating, particularly bedrooms. Many of the bedrooms were found to be warmer at night than during the day due to windows and doors being closed. This practice means nighttime purging of heat is severely hampered throughout the buildings, making them particularly vulnerable to consecutive days of high temperatures. This is also particularly interesting since thermal simulation confirmed night ventilation as the single most impactful passive technique for both buildings. This is also particularly 
interesting since thermal simulation confirmed nighttime ventilation as the single most impactful passive technique for both buildings under current climate. The combination of all of the investigated passive measures - nighttime ventilation, external shading and high-albedo materials on external walls proved to be the most effective passive technique, but implementing all of these measures would be more expensive. However for $2080 \mathrm{~s}$, the higher outdoor temperatures made nighttime ventilation much less effective. The most effective solution, continuous use of airconditioning, was also, naturally, the most energy intensive, highlighting the importance of finding the most appropriate balance between indoor temperature reduction and cooling load on a case-by-case basis. Where the implementation of passive measures alone is not sufficient, their combination with active cooling is likely to enable care homes that remain comfortable for longer and require less cooling.

Care homes are by their very nature hybrid buildings, serving both as living spaces for the residents and offices/workspaces for the staff. It is vital to provide adequate comfort to both residents and staff occupying these buildings particularly during periods of hot weather. The need for an overheating metric tailored for care homes is clearly evident. It is recommended that further research is conducted to gather empirical data - both objective measures of the indoor environments and subjective occupant feedback on perceptions of thermal comfort and preference - which can be used to support the development of a bespoke metric for these vulnerable settings.

\section{CRediT authorship contribution statement}

Rajat Gupta: Conceptualization, Methodology, Formal analysis, Writing - original draft, Writing - review \& editing, Supervision, Funding acquisition. Alastair Howard: Methodology, Formal analysis, Writing - original draft, Writing - review \& editing. Mike Davies: Conceptualization, Methodology, Formal analysis, Writing - review \& editing, Supervision, Funding acquisition. Anna Mavrogianni: Conceptualization, Formal analysis, Writing - review \& editing, Supervision, Funding acquisition. Ioanna Tsoulou: Software, Writing - original draft, Writing - review \& editing. Nishesh Jain: Software, Writing - original draft, Writing - review \& editing. Eleni Oikonomou: Software, Writing - original draft, Writing - review \& editing. Paul Wilkinson: Conceptualization, Methodology, Supervision, Funding acquisition.

\section{Declaration of Competing Interest}

The authors declare that they have no known competing financial interests or personal relationships that could have appeared to influence the work reported in this paper.

\section{Acknowledgements}

The authors would like to thank NERC (Grant ref: NE/ S016767/1) for funding the ClimaCare research project. The authors are grateful to the case study care homes for their engagement in the project and assistance in data collection. We acknowledge financial support provided by DesignBuilder Software Ltd. and Innovate UK funded KTP project (Partnership number 11615). This research was performed in compliance with UK laws and guidelines and approved by University College London's and Oxford Brookes University's research ethics committees.

\section{References}

[1] V. Abrahamson, R. Raine, Health and social care responses to the Department of Health Heatwave Plan, J. Publ. Health 31 (2009) 478-489.
[2] M. Al-Hasan, B. Lahr, J.E. Eckel-Passow, L. Baddour, Seasonal variation in Escherichia coli bloodstream infection: a population-based study, Clin. Microbiol. Infect. 15 (2009) 947-950.

[3] D.O. Åström, F. Bertil, R. Joacim, Heat wave impact on morbidity and mortality in the elderly population: a review of recent studies, Maturitas 69 (2011) 99105.

[4] S. Barnes, J. Torrington, R. Darton, J. Holder, A. Lewis, K. McKee, A. Netten, A. Orrell, Does the design of extra-care housing meet the needs of the residents? A focus group study, Ageing Soc. 32 (2012) 1193.

[5] A. Beizaee, K.J. Lomas, S.K. Firth, National survey of summertime temperatures and overheating risk in English homes, Build. Environ. 65 (2013) 1-17.

[6] British Standards Institution 2008. BS EN 15603:2008, Energy Performance of Buildings - Overall Energy Use and Definition of Energy Ratings. In: BSI (ed.). London.

[7] S. Brown, G. Walker, Understanding heat wave vulnerability in nursing and residential homes, Build. Res. Inf. 36 (2008) 363-372.

[8] S.J. Brown, In the heat of power: Understanding vulnerability to heatwaves in care homes for older people, Lancaster University, 2010.

[9] N. Bundle, E. O'Connell, N. O'Connor, A. Bone, A public health needs assessment for domestic indoor overheating, Public Health 161 (2018) 147-153.

[10] D. Coley, T. Kershaw, M. Eames, A comparison of structural and behavioural adaptations to future proofing buildings against higher temperatures, Build. Environ. 55 (2012) 159-166.

[11] Competition \& Authority, M. 2017. Care homes market study: summary of final report.

[12] S. Conti, P. Meli, G. Minelli, R. Solimini, V. Toccaceli, M. Vichi, C. Beltrano, L. Perini, Epidemiologic study of mortality during the Summer 2003 heat wave in Italy, Environ. Res. 98 (2005) 390-399.

[13] Defra 2017. UK Climate Change Risk Assessment. In: DEFRA (ed.). London, UK: UK Government.

[14] DEFRA 2018. The National Adaptation Programme and the Third Strategy for Climate Adaptation Reporting. In: DEFRA (ed.). London: UK Government.

[15] Designbuilder Software Ltd. 2019. Design Builder V6 [Online]. Available: https:// designbuilder.co.uk/download/release-software, (accessed 17/01/2021).

[16] J. Dewing, Sundowning in older people with dementia: evidence base, nursing assessment and interventions, Nursing older people, 2003.

[17] DOE, 2019. Energy Plus [Online],available: https://energyplus.net/, (accessed 02/02/2020)

[18] A. Gasparrini, Y. Guo, F. Sera, A.M. Vicedo-Cabrera, V. Huber, S. Tong, M.D.S.Z.S. Coelho, P.H.N. Saldiva, E. Lavigne, P.M. Correa, Projections of temperaturerelated excess mortality under climate change scenarios, Lancet Planetary Health 1 (2017) e360-e367.

[19] O. Guerra-Santin, C. Tweed, Summer post occupancy evaluation of a Passivhaus care home in the UK, PLEA (2013).

[20] R. Gupta, L. Barnfield, M. Gregg, Overheating in care settings: magnitude, causes, preparedness and remedies, Build. Res. Inf. 45 (2017) 83-101.

[21] R. Gupta, M. Gregg, Care provision fit for a warming climate, Architect. Sci. Rev. 60 (2017) 275-285.

[22] R. Gupta, G. Walker, A. Lewis, L. Barnfield, M. Gregg, L. Neven, Care provision fit for a future climate, Joseph Rowntree Foundation, 2016.

[23] S. Hajat, R.S. Kovats, R.W. Atkinson, A. Haines, Impact of hot temperatures on death in London: a time series approach, J. Epidemiol. Community Health 56 (2002) 367-372.

[24] S. Hajat, R.S. Kovats, K. Lachowycz, Heat-related and cold-related deaths in England and Wales: who is at risk?, Occup Environ. Med. 64 (2007) 93-100.

[25] S. Hajat, S. Vardoulakis, C. Heaviside, B. Eggen, Climate change effects on human health: projections of temperature-related mortality for the UK during the 2020s, 2050s and 2080s, J. Epidemiol. Community Health 68 (2014) 641648.

[26] C. Hughes, S. Natarajan, Summer thermal comfort and overheating in the elderly, Build. Serv. Eng. Res. Technol. 40 (2019) 426-445.

[27] N. Jain, E. Burman, S. Stamp, D. Mumovic, M. Davies, Cross-sectoral assessment of the performance gap using calibrated building energy performance simulation, Energy Build. 224 (2020) 110271.

[28] H. Johnson, R.S. Kovats, G. McGregor, J. Stedman, M. Gibbs, H. Walton, L. Cook, E. Black, The impact of the 2003 heat wave on mortality and hospital admissions in England, Health Stat. Q. (2005) 6-11.

[29] R.S. Kovats, H. Johnson, C. Griffith, Mortality in southern England during the 2003 heat wave by place of death, Health stat Q 29 (2006) 6-8.

[30] A. Lewis, Energy use in an ageing society: The challenges of designing energyefficient older people's housing, in: Manchester Memoirs-Being The Memoirs and Proceedings of the Manchester Literary and Philosophical Society, 2014, pp. 20-32.

[31] A. Lewis, Designing for an imagined user: Provision for thermal comfort in energy-efficient extra-care housing, Energy Policy 84 (2015) 204-212.

[32] K.J. Lomas, R. Giridharan, Thermal comfort standards, measured internal temperatures and thermal resilience to climate change of free-running buildings: A case-study of hospital wards, Build. Environ. 55 (2012) 57-72.

[33] K.J. Lomas, S. Oliveira, P. Warren, V. Haines, T. Chatterton, A. Beizaee, E. Prestwood, B. Gething, Do domestic heating controls save energy? A review of the evidence, Renew. Sustain. Energy Rev. 93 (2018) 52-75.

[34] R. Luff, T. Ellmers, I. Eyers, E. Young, S. Arber, Time spent in bed at night by care-home residents: choice or compromise?, Ageing Soc 31 (2011) 12291250.

[35] J. Martin, T. Shochat, S. Ancoli-Israel, Assessment and treatment of sleep disturbances in older adults, Clin. Psychol. Rev. 20 (2000) 783-805. 
[36] A. Mavrogianni, M. Davies, J. Taylor, Z. Chalabi, P. Biddulph, E. Oikonomou, P. Das, B. Jones, The impact of occupancy patterns, occupant-controlled ventilation and shading on indoor overheating risk in domestic environments, Build. Environ. 78 (2014) 183-198.

[37] A. Mavrogianni, J. Taylor, M. Davies, C. Thoua, J. Kolm-Murray, Urban social housing resilience to excess summer heat, Build. Res. Inf. 43 (2015) 316-333.

[38] P. Murage, S. Hajat, R.S. Kovats, Effect of night-time temperatures on cause and age-specific mortality in London, Environ. Epidemiol. 1 (2017) e005.

[39] L. Neven, G. Walker, S. Brown, Sustainable thermal technologies and care homes: Productive alignment or risky investment?, Energy Policy 84 (2015) 195-203

[40] J.F. Nicol, M. Humphreys, Understanding the adaptive approach to thermal comfort, ASHRAE Trans. 104 (1998) 991-1004.

[41] PHE ,2020. Heatwave Plan for England. In: ENGLAND, P. H. (ed.). London, UK: UK Government.

[42] Population Reference Bureau 2020. Countries with the oldest populations in the world.

[43] S.M. Porritt, P.C. Cropper, L. Shao, C.I. Goodier, Ranking of interventions to reduce dwelling overheating during heat waves, Energy Build. 55 (2012) 1627.

[44] Public Health England, 2014. Heatwave plan for England-making the case: The impact of heat on health-now and in the future. Department of Health London.
[45] E.S. Quigley, The energy and thermal performance of UK modular residential buildings, Loughborough University, 2017.

[46] J.-L. Salagnac, Lessons from the 2003 heat wave: a French perspective, Build. Res. Inf. 35 (2007) 450-457.

[47] F. Salata, I. Golasi, W. Verrusio, E. De Lieto Vollaro, M. Cacciafesta, A. De Lieto Vollaro, On the necessities to analyse the thermohygrometric perception in aged people. A review about indoor thermal comfort, health and energetic aspects and a perspective for future studies, Sustain. Cities Soc. 41 (2018) 469480.

[48] O.G. Santin, A. Grave, S. Jiang, C. Tweed, M. Mohammadi, Monitoring the performance of a Passivhaus care home: lessons for user-centric design, J. Build. Eng. 102565 (2021).

[49] The World Bank 2019. Population ages 65 and above (\% of total population) United Kingdom.

[50] C. Tweed, N. Humes, G. Zapata-Lancaster, The changing landscape of thermal experience and warmth in older people's dwellings, Energy Policy 84 (2015) $223-232$.

[51] United Nations, Department of Economic and Social Affairs - Population Dynamics - World Population Prospects, 2019.

[52] G. Walker, S. Brown, L. Neven, Thermal comfort in care homes: vulnerability, responsibility and 'thermal care', Build. Res. Inf. 44 (2016) 135-146. 